OPEN ACCESS

Edited by:

Zhiguo Chen,

Capital Medical University, China

Reviewed by:

Yilong Wang,

Capital Medical University, China Benedetta Bussolati,

University of Turin, Italy

*Correspondence:

Anwen Shao

21118116@zju.edu.cn

Lin Wang

dr_wang@zju.edu.cn

${ }^{\dagger}$ These authors have contributed equally to this work

Specialty section:

This article was submitted to

Stem Cell Research,

a section of the journal

Frontiers in Cell and Developmental

Biology

Received: 28 December 2020 Accepted: 05 March 2021 Published: 01 April 2021

Citation:

Zhou G, Wang Y, Gao S, Fu X, Cao $Y$, Peng $Y$, Zhuang J, Hu J, Shao A and Wang L (2021) Potential Mechanisms and Perspectives in Ischemic Stroke Treatment Using

Stem Cell Therapies.

Front. Cell Dev. Biol. 9:646927. doi: 10.3389/fcell.2021.646927

\section{Potential Mechanisms and Perspectives in Ischemic Stroke Treatment Using Stem Cell Therapies}

\author{
Guoyang Zhou ${ }^{+}$, Yongjie Wang ${ }^{+}$, Shiqi Gao, Xiongjie Fu, Yang Cao, Yucong Peng, \\ Jianfeng Zhuang, Junwen Hu, Anwen Shao* and Lin Wang* \\ Department of Neurosurgery, The Second Affiliated Hospital, School of Medicine, Zhejiang University, Hangzhou, China
}

Ischemic stroke (IS) remains one of the major causes of death and disability due to the limited ability of central nervous system cells to regenerate and differentiate. Although several advances have been made in stroke therapies in the last decades, there are only a few approaches available to improve IS outcome. In the acute phase of IS, mechanical thrombectomy and the administration of tissue plasminogen activator have been widely used, while aspirin or clopidogrel represents the main therapy used in the subacute or chronic phase. However, in most cases, stroke patients fail to achieve satisfactory functional recovery under the treatments mentioned above. Recently, cell therapy, especially stem cell therapy, has been considered as a novel and potential therapeutic strategy to improve stroke outcome through mechanisms, including cell differentiation, cell replacement, immunomodulation, neural circuit reconstruction, and protective factor release. Different stem cell types, such as mesenchymal stem cells, marrow mononuclear cells, and neural stem cells, have also been considered for stroke therapy. In recent years, many clinical and preclinical studies on cell therapy have been carried out, and numerous results have shown that cell therapy has bright prospects in the treatment of stroke. However, some cell therapy issues are not yet fully understood, such as its optimal parameters including cell type choice, cell doses, and injection routes; therefore, a closer relationship between basic and clinical research is needed. In this review, the role of cell therapy in stroke treatment and its mechanisms was summarized, as well as the function of different stem cell types in stroke treatment and the clinical trials using stem cell therapy to cure stroke, to reveal future insights on stroke-related cell therapy, and to guide further studies.

Keywords: stem cell, cell therapy, ischemic stroke, transplantation, clinical trial, regenerative medicine

\section{INTRODUCTION}

Stroke is a common cerebrovascular disease with high rates of fatality and disability (Feigin et al., 2017) and is the second leading cause of death, with 5.5 million deaths every year (GBD 2016 Stroke Collaborators, 2019; Lindsay et al., 2019). In the acute phase of ischemic stroke (IS), mechanical thrombectomy (MT), and the administration of tissue plasminogen activator (tPA) can recanalize the occlusive lesion. However, these approaches are limited by the narrow time window for application of 3-4.5 h after IS onset in case of thrombolytic therapy (Roth, 2011; 
Wardlaw et al., 2014) and up to $24 \mathrm{~h}$ after stroke onset in case of MT, depending on imaging criteria (Thomalla and Gerloff, 2019), and only $5-10 \%$ of patients are eligible to receive a reperfusion treatment (Mozaffarian et al., 2016). In the subacute to chronic phases, stroke treatment strategies may be changed to long-term antiplatelet or anticoagulation drugs depending on patients' condition (Bala et al., 2020) or intervention in patients' risk factors of stroke such as hypertension, diabetes, and hypercholesterolemia (Rundek and Sacco, 2008; Tziomalos et al., 2009). While these treatments show significant benefits in stroke patients, they are still not enough to ensure an acceptable quality of life. Recently, cell therapy has gained much attention as a potential IS treatment, since the results obtained so far suggest it has a bright future. Several types of cell therapy are available, including stem cell therapy (Suda et al., 2020), polarized cell therapy (Jiang et al., 2013), and genetic modification or pretreatment stem cell therapy (Kurozumi et al., 2005; Damasceno et al., 2020). In recent years, stem cell therapy has garnered more attention due to its satisfactory results in some preclinical and clinical studies. We believe that stem cell therapy will make an important contribution to the field of stroke treatment, and further research will compliment and add to the successful results seen when using other cell types. The stem cells used in cell therapy include mesenchymal stem cells (MSCs), neural stem cells (NSCs), induced pluripotent stem cells (iPSCs), hematopoietic stem cells (CD34-positive) (HSCs), dental pulp stem cells (DPSCs), embryonic stem (ES) cells (ESCs), and multilineage-differentiating stress-enduring cells (Muse cells) (Chen et al., 2001; Yang et al., 2016; Niizuma et al., 2018; Rikhtegar et al., 2019). The potential mechanisms underlying the protective role of stem cells have been extensively studied, such as the promotion of angiogenesis and endogenous neurogenesis, immunomodulatory functions, differentiation into cells that facilitate repair or replacement of a damaged tissue, secretion of cytokines helping to restore neural injury, and cell migration (Gutiérrez-Fernández et al., 2013; Shichinohe et al., 2015; Tan et al., 2018; Rikhtegar et al., 2019; Kikuchi-Taura et al., 2020). This review summarizes and discusses the pathophysiological changes after IS, which are also the treatment targets of stem cell therapy, the current types of cell therapy, the stem cell used, and the neuroprotective mechanisms. Clinical studies on stem cell stroke therapy are discussed along with the choice of stem cell types, time of transplantation, route of administration, and cell dose, as these are regarded as controversial and worrying aspects by clinicians and neuroscientists.

\section{POTENTIAL THERAPEUTIC TARGETS OF STEM CELL THERAPY IN ISCHEMIC STROKE}

Ischemic stroke accounts for $71 \%$ of strokes and is the treatment target in most stroke trials (Feigin et al., 2018). In the past decades, the pathophysiological changes after stroke have been extensively investigated. Understanding the changes in the microenvironment and cell activities that occur after IS can help to focus on the potential effective role of stem cell therapy, and the pathophysiological changes may also be potential stem cell therapy targets.

\section{Blood-Brain Barrier Disruption}

The BBB plays a vital role in the protection of the central nervous system (CNS) (Daneman and Prat, 2015). The basic structure of the BBB consists of endothelial cells (ECs), astrocytes, and pericytes, with the ECs fused together by intercellular junctions such as tight junctions (TJs) and adherent junctions (AJs). After the onset of stroke, the BBB can be disrupted, followed by the extravasation of blood components into the brain, thus compromising the normal neuronal function. BBB dysfunction is characterized by the structural disruption of the intercellular junctions and increased vascular permeability, which allows the components of the peripheral blood system to cross into the parenchyma more easily. After IS, BBB permeability is increased and cell adhesion molecules are upregulated in the activated endothelium, and peripheral immune cells can access the parenchyma. The infiltrating leukocytes can contribute to BBB dysfunction and injury progression (Shi et al., 2019), and neutrophils are another important peripheral immune cell type that can cross the damaged BBB. In addition to the release of chemokines (Nathan, 2006), activated neutrophils can increase the formation of neutrophil extracellular traps (NETs), which contain double-stranded DNA, histone, and granule proteins including neutrophil elastase, cathepsin G, and myeloperoxidase (MPO) (Urban et al., 2009). The latest research suggests that reduced neovascularization and increased BBB damage can be observed under the increased formation of NETs induced by the overexpression of peptidylarginine deiminase 4 , while the inhibition of this process by DNase 1 , genetic ablation, or pharmacologic administration improves BBB function (Kang et al., 2020).

\section{Neuroinflammation and Immune Response}

Neuroinflammation after stroke is a sterile inflammation defined as an inflammatory response by cells of the innate or adaptive immune systems within the CNS. In IS, neuronal and nonneuronal cell death can produce damage-associated molecular patterns (DAMPs) because of oxygen and glucose deprivation (OGD). During ischemia, DAMPs can activate astrocytes and microglia, increasing production of pro-inflammatory cytokines and chemokines. Peripheral blood then invades the infarcted area, leading to the exacerbation of tissue damage (Dabrowska et al., 2019a). After DAMPs are released into the brain parenchyma, microglia cells are the first line of defense. They secrete pro-inflammatory cytokines, such as tumor necrosis factor- $\alpha$ (TNF- $\alpha)$, NF- $\kappa$ B, interleukin (IL)-1 $\beta$, IL-12, IL-23, and nitrogen monoxide (NO), which induce tissue damage (Benakis et al., 2014; Xiong et al., 2016). Recently the inflammasome, which is a multi-molecular protein complex and one of the intracellular typical pattern recognition receptors (PRRs) located in neurons, microglia, astrocytes after IS, has attracted a lot of attention. The members of the nucleotide-binding domain (NOD)-like receptor (NLR) family including the NODs, 
the NLRPs, and the IPAF subfamilies exhibit inflammasome activity (Mohamed et al., 2015). The NLRP3 inflammasome can cleave pro-IL-1 and pro-IL-18, which become mature IL1 and IL-18 (Alishahi et al., 2019). Neutrophils are among the first cells to arrive into the lesion within the first hour after IS (Garcia et al., 1994) and leukocytes invading the CNS release pro-inflammatory factors in the ischemic region. Neutrophils increase the recruitment of leukocytes by degranulation of their content rich in cytokines/chemokines, free radicals, proteolytic enzymes, and activated-complement system, which in turn exacerbates neuroinflammation (Mayadas et al., 2014). Recently, the detrimental role of neutrophils in IS has been demonstrated. The release of pro-inflammatory cytokines/chemokines, proteases, and oxygen radicals (Neumann et al., 2015), combined with the antagonistic effect of some chemokines such as $\mathrm{C}-\mathrm{X}-\mathrm{C}$ motif chemokine receptor 2 (CXCR-2) and (C-X-C motif) ligand 1 (CXCL-1), can prevent neutrophil recruitment into the infarcted area and reduce the experimental infarcted volume (Gelderblom et al., 2012; Herz et al., 2015).

\section{Excitotoxicity}

Excitotoxicity was first described in 1986 to describe the ability of glutamate and structurally related excitatory amino acids to destroy neurons (Olney, 1969). Glutamate is the main excitatory neurotransmitter in the CNS. The OGD resulting from the interruption of blood flow in IS disrupts ATP supply, which leads to perturbation of the transmembrane gradient, impairment of the neuronal signaling, and neurotransmitter release as a result of anoxic depolarization (Obrenovitch et al., 1993). Depolarization leads to a transient neurotransmitter release, and the reuptake of excitatory neurotransmitters from the synaptic cleft is an ATP-dependent process. Therefore, ischemia leads to an increase in extracellular neurotransmitter concentrations. $N$-Methyl-D-aspartate (NMDA) is a glutamate receptor that plays a key role in excitotoxicity, and in a normal physiological state, its function is controlled by extracellular magnesium and the resting membrane potential. However, after IS, neuronal depolarization removes magnesium, and the NMDA receptor is activated, leading to calcium influx. The primary influx then induces the secondary release of large amounts of calcium from the intracellular environment leading to cell death (Choi, 1992; Lai et al., 2014; Chamorro et al., 2016). To deal with the high concentration of intracellular calcium, mitochondria sequester the majority of the intracellular calcium after glutamate excitotoxicity (Wang and Thayer, 1996). The increase in the glutamate concentration can also activate the $\alpha$-amino-3hydroxy-5-methyl-4-isoxazolepropionic acid (AMPA) receptors, which in normal conditions are not calcium permeable (Peng et al., 2006), but after IS, permeability increases up to 18-fold, contributing to calcium-dependent cell death (Liu et al., 2006).

\section{Oxidative Stress}

After the onset of IS, the balance between pro-oxidants [such as reactive oxygen species (ROS)] and antioxidants is compromised, leading to oxidative stress and damage of the cell structures, including lipids, proteins, and DNA, finally leading to cell death (Zhao et al., 2016). ROS greatly contributes to lipid peroxidation after IS by increasing the production of conjugated dienic hydroperoxides (Adibhatla and Hatcher, 2010) and can decompose the $\omega-6$ polyunsaturated fatty acids into 4-hydroxynonenal (4-HNE), a traditional marker of oxidative stress (Niki, 2009). 4-HNE can enhance apoptosis/autophagy and increase the cerebral infarct area (Lee et al., 2012). Phospholipase A2 (PLA2) is another contributor to lipid peroxidation that can lead to the hydrolysis of membrane phospholipids and the release of free fatty acids. At a high ROS concentration, lipid peroxides are formed and degraded into active aldehydes, which can bind to proteins or nucleic acids, causing neuronal damage (Muralikrishna Adibhatla and Hatcher, 2006). The products of lipid peroxidation such as malondialdehyde (MDA), 4-HNE, and acrolein participate in oxidative stress injury on proteins (Del Rio et al., 2005; Moghe et al., 2015). Oxidative stress can also cause cell death by damaging the DNA (Li et al., 2011). This damage activates the DNA repair signal, which includes the activation of poly(ADP-ribose) polymerase-1 (PARP-1). To repair the DNA strand, $\beta$-nicotinamide adenine dinucleotide $\left(\mathrm{NAD}^{+}\right)$is consumed by PARP-1, which can result in impairment of $\mathrm{NAD}^{+}$dependent processes, including mitochondrial respiration, leading to ATP starvation and, eventually, neuronal death (Southan and Szabó, 2003).

\section{CELL THERAPY}

Because IS involves complex pathophysiological processes, one targeted therapeutic strategy is far from enough. The use of cell therapy, including stem cells, gene-modified stem cells, and polarized cell therapy, has been widely discussed in preclinical or clinically studies. After the onset of IS, CNS cells cannot completely replace the lost or compromised ones because of their limited regeneration and differentiation ability. Stem cells have emerged as a novel and promising option due to their capacity for self-renewal, homing, and multilineage differentiation (Birbrair, 2017; Huang et al., 2018). A variety of stem cell types derived from neural and non-neural tissues have been widely studied as potential donors for IS treatment.

Neurotrophic factor secretion is an important mechanism underlying the function of stem cell therapy in IS. Growth factors such as brain-derived neurotrophic factor (BDNF), vascular endothelial growth factor (VEGF), and erythropoietin (EPO) are involved in the restoration of the damaged tissue to prevent neuronal death (Schäbitz et al., 2000), angiogenesis, anti-inflammation, or brain repair after IS. Therefore, genemodified stem cells, which can overexpress different growth factors or cytokines through gene transfection, will possess a unique superiority in terms of injury repair compared with unmodified stem cells (Geiseler and Morland, 2018).

The phenotypes of several CNS cells, such as microglia, macrophages, astrocytes, and neutrophils, are in a dynamic flux and can thus exhibit two different phenotypes: the classic pro-inflammatory type and alternative protective type. After the onset of IS, the pro-inflammatory phenotype 
cells increase inflammatory mediators inducing brain tissue injury (Block et al., 2007; Kanazawa et al., 2017b; Liddelow and Barres, 2017), while the anti-inflammatory phenotype cells can secrete neurotrophic factors and protective cytokines (Imai et al., 2007; Crain et al., 2013), which have a neuroprotective function (Schäbitz et al., 2000; Hu et al., 2012; Dudvarski Stankovic et al., 2016; Geiseler and Morland, 2018). When considering classical or gene-modified stem cells, ethical issues and tumorigenicity must be taken into account, as highlighted in previous studies (Murry and Keller, 2008; Ratajczak et al., 2019). Targeting microglia or other polarized cells after IS may be an optional cell therapy strategy. Because of the lack of relevant research, the specific protective function should be a focus of future studies (Hatakeyama et al., 2020b).

\section{DIFFERENT STEM CELL TYPES IN CELL THERAPY}

\section{Mesenchymal Stem Cells}

Mesenchymal stem cells have the capacity for self-renewal and potential multidirectional differentiation into different cell types and are available from almost any tissue type. The bone marrowderived MSCs (BM-MSCs) are the most widely studied and are capable of differentiating into neurons or glial cells and, thus, are able to replace damaged cells in brain tissues. The ability to differentiate into ECs and release trophic factors such as VEGF, BDNF, glial cell-derived neurotrophic factor (GDNF), and transforming growth factor (TGF), contribute to angiogenesis and neuroprotection (Wakabayashi et al., 2010; Wagenaar et al., 2018). Although MSCs have a high ability to differentiate into neuronal lineage cells and migrate into ischemia lesions, only a small proportion of stem cells enter the infarct core area (Modo et al., 2004). The paracrine action or "bystander effect," which relies on the secretion of trophic factors, is the main contributor to the therapeutic effect rather than direct cellular replacement. The trophic factors released from MSCs promote angiogenesis, induce the proliferation and recruitment of endogenous stem cells from the subventricular zone (SVZ) to the infarcted area, and modulate neuroinflammation. MSCs also promote the production of regulatory T cells (Wang et al., 2014), which increase the expression of IL-10, attenuate astrocytes and microglial reactivity, exert an anti-apoptotic effect, and reduce levels of the inflammatory cytokines IL-1 $\beta$ and IL-6 (Zhu et al., 2014; Sotomayor-Sobrino et al., 2019).

\section{Multilineage-Differentiating Stress-Enduring Cells}

Multilineage-differentiating stress-enduring cells are characterized by self-renewal and multipotency and can differentiate into all three germ layers (Wakao et al., 2011; Heneidi et al., 2013; Dezawa, 2016). MUSE cells are found in the bone marrow, adipose, dermis, and connective tissues (Heneidi et al., 2013; Gimeno et al., 2017) and can be purchased or collected from human tissues. After the first report on MUSE cells in 2010 (Kuroda et al., 2010), several other studies have investigated their therapeutic potential in diseases such as acute myocardial infarction (MI), liver disease, and chronic kidney disease (CKD) (Katagiri et al., 2016; Yamada et al., 2018). In normal conditions, MUSE cells are inactive. After IS, the ischemia insult stimulates MUSE cell mobilization from the bone marrow into the peripheral blood flow (Hori et al., 2016). MUSE cells effectively migrate into the infarcted area where they differentiate into neural cells to restore the damaged brain tissues. Their efficient migration has also been observed in other diseases including MI, CKD, and liver disease (Uchida N. et al., 2017; Yamada et al., 2018). After reaching the ischemic area, MUSE cells can replace the damaged cells by differentiating into neuronal-lineage cells (Uchida et al., 2016; Abe et al., 2020). The administration of diphtheria toxin (DT) in a rat IS model inhibits recovery, suggesting that the neural circuit reconstruction is a key mechanism underlying the therapeutic effects (Uchida H. et al., 2017; Abe et al., 2020). MUSE cells can also modulate neuroinflammation and immune response by downregulating the secretion of pro-inflammatory cytokines including TNF- $\alpha$ (Gimeno et al., 2017). While tumor formation and other adverse effects have not been reported, some issues remain to be solved, including the appropriate timing, dose, and safety, before their use in clinical practice can progress.

\section{Neural Stem Cells}

Neural stem cells are self-renewing cells and possess the multi-potential to differentiate into neurons, astrocytes, and oligodendrocytes (Boese et al., 2018; Obernier and AlvarezBuylla, 2019; Ottoboni et al., 2020). Exogenous NSCs can be derived from ESCs, iPSCs, fetal tissue, and adult nervous systems. Their abilities to produce primary CNS cells make NSCs promising candidates for the replacement of the damaged or lost cells in the brain tissues after IS. Under normal conditions, neurogenesis persists throughout the whole life in rodents and humans (Boldrini et al., 2018), and endogenous NSCs, found mainly in the dentate gyrus of the hippocampus, the SVZ, and the olfactory bulb in mammals, remain inactive (Obernier and Alvarez-Buylla, 2019). After IS, cytokines or chemokines such as stromal cell-derived factor-1 (SDF-1), VEGF, and monocyte chemoattractant protein (MCP)-1 are released, increasing the proliferation and migration of NSCs from the SVZ into the ischemic area (Mine et al., 2013; Leal et al., 2017; Geiseler and Morland, 2018).Thanks to their strong ability to differentiate into neuronal cells, transplanted NSCs have been shown to be effective in promoting the neurological function recovery in preclinical studies. NSCs can migrate into the ischemic brain area and differentiate into mature neurons to reconstruct the neural circuit (Shetty and Hattiangady, 2016). Exogenous NSCs are also capable of stimulating neurogenesis in the SVZ. NSCs release neurotrophic factors such as BDNF, VEGF, and nerve growth factor (NGF), which can prevent neural apoptosis and improve functional recovery by directly or indirectly increasing the angiogenesis, endogenous neurogenesis, and plasticity of neuronal cells (Shetty and Hattiangady, 2016; Ottoboni et al., 2020). The activation 
of microglia and infiltration of neutrophils also decrease after NSC transplantation, thus relieving neuroinflammation (Lee et al., 2008).

\section{Induced Pluripotent Stem Cells}

Induced pluripotent stem cells are somatic-derived stem cells characterized by an increased translational potential. iPSCs were first established in 2006 by introducing transcription factors into mouse fibroblasts during a pluripotent state (Takahashi and Yamanaka, 2006). This somatic cell-derived feature also gives iPSCs the following advantages over other stem cells: (i) they can be obtained from different sources, and isolation does not require invasive measures; (ii) iPSC culture provides an adequate cell number for transplantation in a shorter time; and (iii) autologous cells show almost no immunogenicity after transplantation (Ojeh et al., 2015; Vitrac and Cloëz-Tayarani, 2018). Furthermore, iPSCs have similar advantages to ESCs in that they are pluripotent, can undergo self-renewal, and can differentiate into cells from three germ layers (Takahashi and Yamanaka, 2006; Takahashi et al., 2007). While their differentiation into neurons, ECs, or astrocytes may improve the overall effect of the treatment, there is also a risk of tumorigenicity (Suda et al., 2020).

\section{Dental Pulp Stem Cells}

Dental pulp stem cells are ectoderm-derived stem cells residing within the dental pulp (Nosrat et al., 2004), which can differentiate into multiple cell types including neural cells, muscle, cartilage, and adipocytes (Dailey et al., 2013). They have similar properties to both NSCs and MSCs in terms of surface markers and biological features (Gronthos et al., 2000; Martens et al., 2013). The expression of nestin, MAP2, the astrocytic marker GFAP, and NeuN by DPSCs has also been reported (Gronthos et al., 2002; Sakai et al., 2012; Foudah et al., 2014), suggesting that they have the potential ability to differentiate into neuron-like cells. In an animal model of spinal cord injury (SCI), transplanted DPSCs improved functional recovery by three mechanisms: (1) decreased CNS cell apoptosis; (2) their paracrine effect minimized the influence of multiple axon growth inhibitors such as chondroitin sulfate proteoglycan and myelin-associated glycoprotein; and (3) they differentiated into mature neural cells and replaced the lost brain tissues (Sakai et al., 2012). DPSCs can also differentiate into dopaminergic neurons and reconstruct immature neural networks (Chun et al., 2016). While they have properties similar to those of MSCs and NSCs, they confer more advantages, their proliferation is significantly faster than that of MSCs (Ponnaiyan and Jegadeesan, 2014), and they can also more effectively reduce the infarcted area and improve motor function compared with MSCs (Song et al., 2017). Moreover, DPSCs secrete specific neurotrophic factors such as GDNF, NGF, and BDNF; and the conditioned medium containing these factors is also a promising novel treatment for IS (Kichenbrand et al., 2019). Finally, DPSCs protect neural cells from oxidative stress by decreasing OGD-induced ROS production (Song et al., 2015) and contributing to immune system modulation by inhibiting $\mathrm{T}$ cell activation and increasing $\mathrm{CD}^{+} \mathrm{T}$ cell apoptosis (Pierdomenico et al., 2005; Demircan et al., 2011).

\section{Hematopoietic Stem Cells (CD34 Positive)}

Hematopoietic stem cells are a rare cell population obtained from the bone marrow, mobilized peripheral blood (MPB), and umbilical cord blood (UCB) (Behzad-Behbahani et al., 2005; Sovalat et al., 2011). HSCs are able to self-renew and can differentiate into a full spectrum of blood cells (Derakhshani et al., 2019). CD34 ${ }^{+}$HSCs were found to invade the peripheral blood after acute stroke (Hennemann et al., 2008). In published studies, HSCs are almost all CD34 positive (Uemura et al., 2012) and under normal conditions maintain a quiescent state via the coupling of CXCL12 with CXCR4. After IS, the increase in sympathetic tone and upregulation of granulocyte colonystimulating factor (G-CSF) promote the mobilization of $\mathrm{CD} 34^{+}$ HSCs, which are recruited to the injured lesion where they can exert a protective effect (Borlongan et al., 2011). CD34 ${ }^{+}$ HSCs from bone marrow and UCB enhance the neuroprotective ability through angiogenesis, neurogenesis, and the regulation of inflammation (Hennemann et al., 2008). HSCs are also feasible, safe, and effective in the treatment of hematologic, cardiovascular, bone, and genetic defect diseases (Borlongan et al., 2011). This may be related to their inability to undergo neuronal differentiation and are thus unable to complete the complex restoration process necessary to repair the damage after IS. However, HSCs can improve neuronal structures through fusion with their residential components and adoption of their phenotype (Terada et al., 2002).

\section{Embryonic Stem Cells}

Embryonic stem cells are isolated from early embryonic or primitive gonads, are immortalized in vitro, and possess selfrenewal and multilineage differentiation abilities (Murry and Keller, 2008). ESCs can be induced to differentiate into almost all somatic cell types when cultured with specific cytokines (Ratajczak et al., 2019). After being considered cells of unlimited potential for regenerative medicine, a variety of problems emerged, causing widespread concern around the world. The first is the ethical issue, which is constantly debated, but other concerns exist, such as tumorigenicity, immune rejection, induction of epigenetic changes, and genetic alterations, which have also been discussed (Murry and Keller, 2008; Ratajczak et al., 2019). It is worth pointing out that the tumorigenicity of ESCs can be reduced by modulating the anti-apoptotic $\mathrm{Bcl}-2$ gene to regulate epigenetic stability (Allegrucci et al., 2007).

Very little research on ESC transplantation in stroke has been done. Striatal transplantation of mouse ESCs in a rat IS model was shown to alleviate neurological dysfunction by improving dopaminergic function (Yanagisawa et al., 2006). Other animal experiments have revealed that ESCs exert a protective effect on cerebral ischemia after generating secondary cells such as neural precursors, neural lineage cells, and NSCs after differential induction in vitro. These inductions can be caused by neurotrophic factors such as BDNF, small molecule inhibitors, co-culture with other cells like bone marrow stromal cells (BMSCs), or other means (Yang et al., 2009; Drury-Stewart et al., 2013; Rosenblum et al., 2015). Although clinical trials in the 
United States have used ESCs to treat SCI (Ilic et al., 2015), their use is not widespread due to theoretical and technical difficulties, as well as public opinion.

While different stem cell types have similarities, or overlaps in their protective functions, they each have particular strengths and limitations. MSCs are one of the most studied stem cells; they have a rich research knowledge base, have strong differentiation ability, and are easy to collect but have limited ability to enter the infarct core area. Other stem cells such as MUSE cells and NSCs can efficiently enter the infarct area and reconstruct the neuronal structure. In current research examining the protective function of a specific stem cell, researchers pay greater attention to the role of the "bystander effect," exosomes, and paracrine effect and, thus, to some extent, ignore the basic characteristics of stem cells such as the ability of differentiating into mature cells, which can directly replace the damaged brain tissue. In MUSE cells, iPSCs, and ESCs, the focus has been less on bystander effects and more on their strong ability to differentiate and replace damaged cells and rebuild the neuronal circuit; however, ethical issues and tumorigenicity must be taken into consideration in further ESCs or iPSC research. The role of stem cells is not limited to one cell or mechanism, and there are more stem cell types and mechanisms for us to discover and explore. Further study on induced differentiation, gene-edited stem cells, or finding new stem cell types will greatly advance our current knowledge base.

\section{PROTECTIVE MECHANISMS REGULATING STEM CELL THERAPY AFTER IS}

Stem cell transplantation can improve the IS outcome from different aspects, exerting a variety of protective effects thanks to the pleiotropic mechanisms underlying stem cell therapy. Over the last decades, several stem cell types have been widely studied and even been used in clinical practice. Mechanisms to regulate their therapeutic effects include modulation of neuroinflammation and the immune response, angiogenesis, neurogenesis, secretion of protective factors, and cell migration.

\section{Stem Cell Migration}

The first step in restoring damaged cells following stroke is the migration of stem cells into the damaged brain regions (De Feo et al., 2012); however, it is not yet clear how the stem cells enter the infarct core or boundary area after IS; therefore, modulating their migration remains a challenge in translating stem cell therapy from the laboratory to clinical practice (Sullivan et al., 2015). Understanding this mechanism should be a critical part of future studies on the protective effects of stem cell therapy.

Although endogenous NSCs located in the SVC remain inactive in normal conditions (Obernier and Alvarez-Buylla, 2019), the onset of IS is associated with its activation and recruitment to the adjacent lesioned areas (Nakayama et al., 2010), and the ischemic insult also leads to increased migration, proliferation, and differentiation. During the ischemia condition, the hypoxia-inducible factor- $1 \alpha$ (HIF-1) represents an important transcriptional factor induced by hypoxia itself, which can promote neuroprotection during a particular time window (Yamashita and Abe, 2016). HIF-1 can upregulate EPO release (Li et al., 2020a), which contributes to stem cell migration after IS, while the knockdown of EPO receptors significantly decreases post-stroke neurogenesis by impairing stem cell migration (Tsai et al., 2006). The upregulation of EPO increases BDNF expression, which is neuroprotective in IS. A recent study revealed that although $\mathrm{BDNF}$ administration has no effect on migration speed of stem cells, BDNF treatment of NSCs can result in significant chemotactic and directional migration in CXXL12 gradients compared with untreated NSCs (Xu and Heilshorn, 2013). Due to the role of BDNF in stem cell migration, recent research has shown that a certain level of BDNF can serve as a minimum predictive value for the recovery of motor function after IS (Luo et al., 2019). The mesencephalic astrocyte-derived neurotrophic factor (MANF) also plays a crucial role in regulating neural progenitor cell (NPC) migration and protects endogenous NSCs against OGD-induced injury (Tseng et al., 2018).

As discussed above, the $\mathrm{BBB}$ is a selective barrier composed of ECs, pericytes, and astrocytes; and the TJs and AJs between ECs help the BBB to separate the CNS from the peripheral blood flow. The entrance of transplanted stem cells from the peripheral blood circulation to the brain parenchyma through the $\mathrm{BBB}$ is therefore necessary for stem cells to exert an effective therapeutic effect. The expression of E- and P-selectin in the cerebral microvasculature increases after IS (Huang et al., 2000). A recent study observed increased adhesion of BMSCs in cerebral venules after the IS compared with sham mice, and the immunoneutralization of either E- or P-selectin blocks the recruitment of adherent BMSCs (Yilmaz et al., 2011). These results suggest that ECs exhibit a pro-adhesive phenotype that increases selectin-dependent rolling and adhesion after IS. VCAM-1 is also an adhesion molecule upregulated on EC membrane after IS. Transplanted NSCs can adhere to the VCAM-1 in a static adhesion assay, and CD49 may serve as the critical ligand for VCAM-1-mediated NSC adhesion (Guzman et al., 2008). Laminin signaling can increase the migration of neuroblasts along vascular scaffolds to injured areas via $\beta 1$ integrin (Fujioka et al., 2017). Selectin-mediated rolling and integrin-associated adhesion play important roles in the transendothelial processes of transplanted stem cells, although they can also increase the recruitment and infiltration of neutrophils after the onset of IS, which can aggravate brain damage (Ao et al., 2018); however, its detailed mechanisms need to be further elucidated. After stem cell adhesion to the ECs, CXCL-11 is released, which can bind CXCR-3 and increase the permeability of $\mathrm{BBB}$ by opening the TJs under the activation of ERK1/2 signaling pathway (Feng et al., 2014). Stem cell therapy can also reduce $\mathrm{BBB}$ disruption by preventing the upregulation of MMP-9 and downregulating ICAM-1 in ECs (Cheng et al., 2018). The apparent opposite effect of stem cells on the BBB depends on the different stages of stem cells, an aspect that requires further exploration.

After IS, HIF-1 stimulates the transcription of SDF1/CXCL12 (Ceradini and Gurtner, 2005); and the levels of CXC chemokine receptor 4 (CXCR4), an SDF-1 receptor, increase on the membrane of stem cells (Delcroix et al., 2010; 
Moll and Ransohoff, 2010). SDF-1 binding to CXCR4 activates several signaling pathways such as the phosphatidylinositide-3kinase (PI3K/Akt), ERK1/2, c-Jun N-terminal kinase (JNK), and p38 MAPK pathways, which enhance stem cell migration. The extent to which pathways are activated is influenced by several factors such as the differentiation stage (Chen Y. et al., 2014) and the concentration of SDF-1 (Yu et al., 2016). Despite the interaction between SDF-1 and CXCR4, a recent study found that osteopontin (OPN) is a phosphoglycoprotein constitutively expressed in the brain, which plays an important role in tissue homeostasis. OPN expression upregulates and stimulates the migration of NSCs via CXCR4, resulting in an effective therapeutic effect after IS (Rabenstein et al., 2015). During ischemia, C-C motif chemokine ligand 2 (CCL2), one of the most highly expressed chemokines, contributes to neurological repair; and the interaction between CCL2 and CCR2 (CCL2 receptor) enhances stem cell migration to the infarcted area, promoting subsequent brain repair (Huang et al., 2018; Lee et al., 2020). TLRs are important mediators that cause neuroinflammation but are also involved in brain repair after IS. The ischemic insult induces TLR4 activation, which is involved in the early expression of SDF-1 and faster recovery of BDNF expression, which promotes migration of endogenous neuroblasts (PalmaTortosa et al., 2019). Neuroinflammation is a crucial aspect of IS pathophysiology; and inflammatory chemotactic agents and cytokines such as MCP-1, macrophage inflammatory protein1alpha (MIP-1alpha), and IL-8 expressed in the injured brain can increase stem cell migration into the infarcted areas (Wang et al., 2002; Figure 1).

\section{Modulation of Neuroinflammation and Immune Response}

After the onset of IS, the DAMPs released from the damaged CNS cells bind receptors such as TLRs or nuclear receptors to activate the innate immune system (Benakis et al., 2014), and increase expression of pro-inflammatory cytokines. As previously summarized, the cascade is mediated by the activation of innate immune cells or leukocytes from the peripheral blood infiltrating through the damaged BBB. Transplanted stem cells can ameliorate the inflammatory process and exert a protective function.

To deal with the cascade, transplanted stem cells can decrease the expression of pro-inflammatory cytokines. MSC added to conditioned media can reduce the secretion of IL- 6 and TNF- $\alpha$ by microglia (Dabrowska et al., 2019a; Tobin et al., 2020). The reduction of IL-1 $\beta$, IL- 6 , and TNF- $\alpha$ can also be observed in MSC-treated mice following ischemia (Cheng et al., 2018). Other stem cell types, including NSCs, DPSCs, and iPSCs, can also protect the CNS from damage by pro-inflammatory cytokines (Eckert et al., 2015; Nito et al., 2018). Stem cells can also secrete anti-inflammatory cytokines including IL-4, IL-10, and TGF- $\beta 1$ (Zhang et al., 2016).

In addition to the important role of ameliorating neuroinflammation, different cell types involved in neuroinflammation or the immune response such as macrophages, microglia, astrocytes, and even some antigen presenting cells can also be a stem cell target. DPSCs, for example, possess a potent immunoregulatory function by increasing $\mathrm{CD}^{+} \mathrm{T}$ cell apoptosis and the expression of anti-inflammatory cytokines and by decreasing the expression of pro-inflammatory cytokines (Demircan et al., 2011). BMSCs can also decrease infiltration of gamma delta $\mathrm{T}(\gamma \delta \mathrm{T})$ cells and increase infiltration of regulatory $\mathrm{T}$ cells (Tregs) after IS (Wang et al., 2014). Macrophages co-cultured with MSCs exhibit a phenotype with low secretion of IL- 6 and TNF- $\alpha$ and high expression of IL-10, which is similar to an anti-inflammatory phenotype, indicating that stem cells can modulate the immunophenotype and functional characteristics of macrophages (Kim and Hematti, 2009). MSCs can reduce proliferation of NK cells, cytokine secretion, and the expression of receptors by similar regulatory mechanisms (Valencia et al., 2016). After the onset of IS, the activation of residual cells in the CNS plays an important role in neuroinflammation. NSC transplantation decreases the number of infiltrating microglia, macrophages, inducible nitric oxide synthase (iNOS), and cyclooxygenase (COX)-2 expressing cells (Watanabe et al., 2016) and also reduces cytokine levels (Lee et al., 2008). Furthermore, iPSC transplantation in an SCI model not only reduces the activated macrophages or microglia but also inhibits GFAP-positive cells and glial scar formation. The increasing expression of IL-10 after stem cell transplantation partly accounts for the attenuation of astrocyte reactivity.

In the acute phase of IS, leukocytes invade the brain parenchyma due to the increased BBB permeability and the upregulation of ICAM and VCAM. The results of histologic quantifications in the peri-stroke areas revealed that NSC transplantation decreases $\mathrm{MPO}^{+}$neutrophil infiltration (Lee et al., 2008). Another study revealed that NSC transplantation downregulates ICAM and VCAM, which can, to some extent, repair the BBB (Huang et al., 2014). However, some stem cells cannot directly improve inflammation and immune response by targeting inflammatory factors and immune cells, or maybe their exact mechanism has not yet been discovered. In the chronic phase of IS, some stem cells can indirectly improve neovascularization, neurogenesis, and restoration of $\mathrm{BBB}$, thus exerting anti-inflammatory effects. The recent increase in interest in human pluripotent stem cells (hPSC) is due to the fact that they have the potential to differentiate into cells with $\mathrm{BBB}$ markers and characteristics (Lippmann et al., 2020); thus, their protective effect could be partly due to their ability to restore the BBB. In light of all these discoveries, stem cell therapy represents a potential treatment to protect the CNS through neuroinflammation activity (De Feo et al., 2012; Figure 2).

\section{Secretion of Protective Factors}

Some recent studies have found a lower density of transplanted stem cells in the stroke core compared with the penumbra or surrounding area, suggesting that functional improvements are more likely mediated by the release of trophic factors rather than cell replacement and differentiation, a phenomenon known as the "bystander effect."

The bystander effect is common in the protective mechanisms of stem cell used in the IS therapy. The use of GRID, a contrast agent that allows monitoring of NSCs, revealed that these stem 


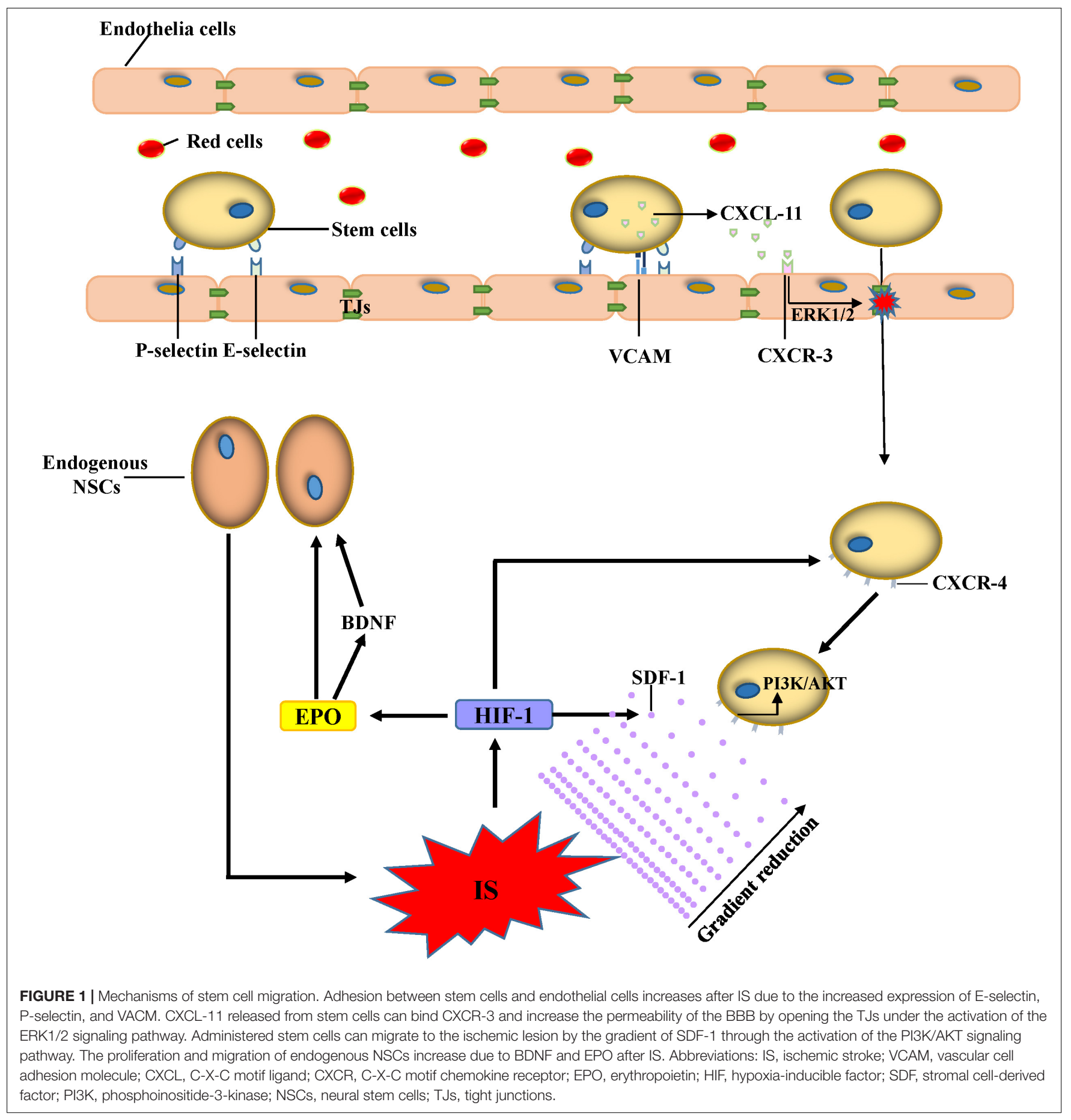

cells migrate to the area around the ischemic infarct instead of the core area in rats (Modo et al., 2004). The change of function and structure of the neuron network was non-invasively monitored using MRI for 3 months after stem cell implantation in rats. It is that revealed the functional network sharply decreased for the entire 3 months, while it was previously stabilized in mice with NSC transplantation, indicating the important paracrine role of stem cell treatment in IS therapy (Green et al., 2018). DPSCs can move into the boundary area of the ischemic lesion and mostly differentiate into glial cells instead of neurons (Song et al., 2017); however, trophic factors such as cytokines, chemokines, and exosomes released by the stem cells can interact with different cells in the CNS to improve the outcome after IS. These factors are released into the microenvironment via direct permeation and extracellular vesicles (EVs) such as exosomes or microvesicles and exert a paracrine effect. In recent years, many studies have shown that microglia, astrocyte, and macrophage activation can be effectively attenuated by neurotrophic factor 


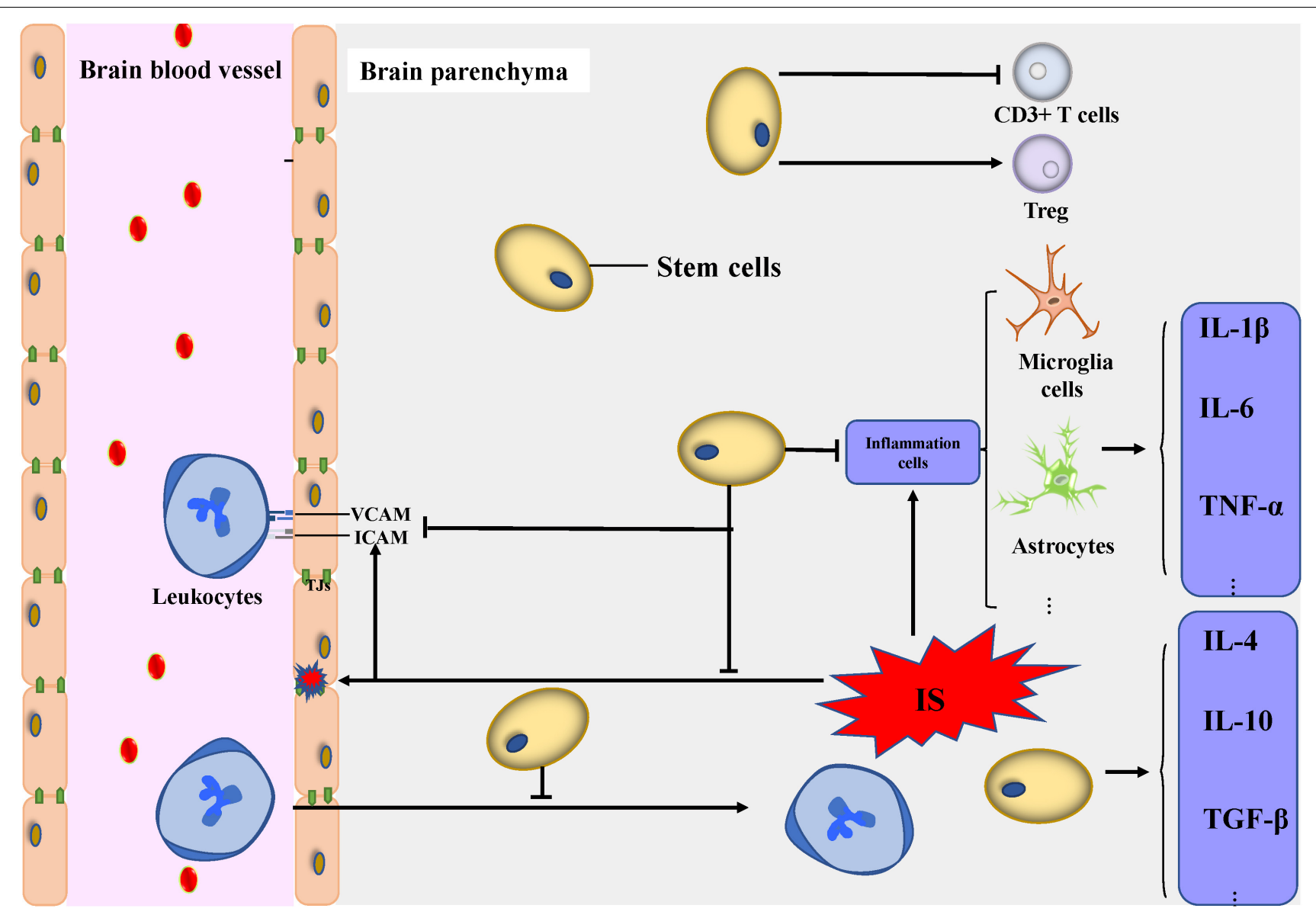

FIGURE 2 | Modulation of neuroinflammation and immune response. Transplanted stem cells can decrease the expression of pro-inflammatory cytokines including $\mathrm{IL}-1 \beta, \mathrm{IL}-6$, and TNF- $\alpha$ and secrete anti-inflammatory cytokines including IL-4, IL-10, and transforming growth factor- $\beta 1$. Transplanted stem cells can modulate the activity of inflammatory cells including microglial cells, astrocytes, and T cells. The infiltration and pro-inflammation effect of leukocytes from peripheral blood decreased under the administration of stem cells. Abbreviations: IS, ischemic stroke; VCAM, vascular cell adhesion molecule; ICAM, intercellular adhesion molecule; IL, interleukin; TNF, tumor necrosis factor; TGF, transforming growth factor; Treg, regulatory T cells; TJs, tight junctions.

secretion (Valencia et al., 2016; Watanabe et al., 2016) after stem cell transplantation. The secretion of high levels of protective cytokines and neurotrophic and angiogenic factors is involved in the paracrine effect after IS (Stonesifer et al., 2017; Geiseler and Morland, 2018), and this effect on stem cells and its role in IS have been recently investigated. After injection with a conditioned medium rich in MSCs, paracrine factors into the lateral ventricle of the middle cerebral occluded artery of rats, the infarct volume and cerebral edema were significantly reduced, and the neurological deficits were improved (Asgari Taei et al., 2020). In rats receiving transplanted stem cells, human insulinlike growth factor 1 (IGF-1) was present in the peri-infarcted area at 3 days, and they had a higher level of neurotrophic factors such as VEGF, epidermal growth factor (EGF), and basic fibroblast growth factor (bFGF) than the control group (Wakabayashi et al., 2010).

Extracellular vesicles have recently received a great deal of recent attention. They are membrane vesicles containing proteins, nucleic acids, and bioactive lipids that can be secreted by different types of cells (Raposo and Stoorvogel, 2013).
After being released from the original cells, EVs enter the neuronal microenvironment; and the content of the original cells, such as membrane and cytosolic lipid, protein, and RNA, is transferred. EVs serve as a mediator, participating in intercellular communication and finally leading to epigenetic changes and functional modifications of neighboring or distant cells. The expression of VEGF and HIF-1 $\alpha$ is upregulated in the core area and ischemic border zone (IBZ) after MSC transplantation, which can increase angiogenesis. When the human microglia cell line (HMO6) and MSCs are co-cultured in vitro, VEGF mRNA increases in both lines, indicating that MSCs increase angiogenesis by a paracrine effect (Sheikh et al., 2019). EVs may be the main intercellular mediator, and those secreted by MSCs can enhance angiogenesis by activating the signal transducer and activator of transcription 3 (STAT3), the suppression of which can abolish the paracrine effect (Xia et al., 2020). EVs from stem cells are rich in various microRNAs (miRNAs), which can target the 3'-untranslated region (UTR) to upregulate VEGF, bFGF, and HIF and activate the PI3K/AKT, Ras/Raf/MEK/ERK/MAPK, and Notch signaling pathways, all of which are associated with 
angiogenesis (Zhu et al., 2015; Guo et al., 2018; Potz et al., 2018; Icli et al., 2019). Due to the lower migration of the transplanted adipose-derived stem cells (ADSCs) into the ischemic core area, a study aiming to discuss the potential paracrine effect of stem cell therapy after IS found that EVs mediate the transfer of miRNA-126, which significantly increases the expression of von Willebrand factor (an EC marker), thus promoting the neurological recovery after stroke (Geng et al., 2019). EVs from stem cells possess the ability to mimic the beneficial effects of the original cells through the transfer of miRNA and functional proteins (Qiu et al., 2018). Stem cells can participate in the inflammatory response and immune modulation after IS and modulate these pathophysiological changes in an indirect manner by the paracrine effect.

After IS, stem cell-derived EVs can reduce neuroinflammation by turning the microglia into an anti-inflammatory phenotype in rhesus monkeys (Go et al., 2020), which modulates neuroinflammation through interaction with immune recipient cells (Spellicy and Stice, 2020). In addition to microglia inhibition, EVs isolated from MSCs attenuate the activation of astrocytes and $\mathrm{T}$ cytotoxic cells, resulting in the inhibition of the expression of pro-inflammatory cytokines such as IL-1, IL-6, and TNF- $\beta$ (Dabrowska et al., 2019b). After lipopolysaccharide (LPS) stimulation, the administration of stem cell-derived exosomes results in a decrease in astrocyte activation as well as a decrease in expression of TNF- $\alpha$, IL-1 $\beta$, and IL- 6 . These effects suggest that the paracrine effect ameliorates inflammation-induced astrocyte alterations (Xian et al., 2019). The immunomodulatory mechanisms are also established between transplanted stem cells and $\mathrm{T}$ cells by paracrine interaction. The paracrine factors released from MSCs suppress $\mathrm{CD}^{+}{ }^{+}$Tbet $^{+}$(Th1) and $\mathrm{CD}^{+}{ }^{+}$ $\mathrm{Gata}^{+}$(Th2) cells but stimulate $\mathrm{CD} 4^{+}-\mathrm{Stat} 3^{+}$(Th17) and $\mathrm{CD}^{+}{ }^{+}-\mathrm{CD} 25^{+}-\mathrm{FoxP}^{+}$(Treg) cells (Özdemir et al., 2016). The paracrine effect also has strong immunoregulatory functions contributing to the apoptosis of CD3 (+) T cells when cocultured with DPSCs (Demircan et al., 2011). The beneficial paracrine effect of stem cell support and protect neurons in ischemic conditions, which is largely attributed to the release of neurotrophic factors such as SDF, NGF, BDNF, GDNF, and FGF (Wakabayashi et al., 2010). The infarct volume in IS rats significantly decreases after MSC transplantation into the infarcted area, accompanied by an increase in bFGF and SDF expression near the infarcted cortex compared with the control group rats (Toyoshima et al., 2015). NSC transplantation can also enhance neurogenesis and activate Akt and Erk1/2 signaling through the release of GDNF after IS (Yuan et al., 2013).

Although the neurotrophic factors mentioned above can protect neurons, some miRNAs also exhibit a beneficial function as intercellular messengers. Exosomes from stem cells containing miR-17-92 have significantly robust beneficial effects in the improvement of the neurological function, and they can rescue the boundary area of the infarcted lesion by enhancing neuronal dendrite plasticity and neurite remodeling (Xin et al., 2017). After IS, ADSC-derived exosomes containing miR-126 increase von Willebrand factor and doublecortin (a neuroblast marker) expression, decrease neuronal death, and increase neuron proliferation, improving neuronal functional in IS rats
(Geng et al., 2019). Endogenous NSCs and NPCs are located mainly in the dentate gyrus of the hippocampus, the SVZ, and the olfactory bulb and are normally inactive (Obernier and AlvarezBuylla, 2019); however, the paracrine effect of transplanted cells can promote the proliferation and migration of endogenous NPCs to the injured brain areas (Leal et al., 2017; Geiseler and Morland, 2018). In recent years, interest in the benefits of the paracrine effect of stem cells transplantation has increased the attention on EVs and exosomes due to their low immunogenicity and high $\mathrm{BBB}$ permeability and therefore are a potential IS treatment (Figure 3).

\section{Angiogenesis and Blood-Brain Barrier Repair}

Temporary or permanent blood flow deficiency is considered to be the initial cause of a series of pathophysiological changes during IS, and the destruction of BBB directly related to vascular injury is a vital pathological change leading to hemorrhage and poor prognosis (Jiang et al., 2018). Increasing microvessel density and the repair of the damaged $\mathrm{BBB}$ to reconstruct the blood flow to the core ischemic area to re-establish the supply of oxygen and nutrients may represent another potentially relevant treatment. Several animal experiments have shown that a variety of stem cells can induce angiogenesis and BBB repair after IS (Uemura et al., 2012; Wang J. et al., 2013; Wang et al., 2015; Zhu et al., 2015; Muir et al., 2020).

Angiogenesis is the formation of new microvessels that branch off from preexisting capillaries (Hatakeyama et al., 2020a). The increased microvessel density and TJ protein (occludin) expression in the border of the animal ischemic core suggest that angiogenesis and $\mathrm{BBB}$ repair occur after stem cell treatment (Zacharek et al., 2007). These effects can be divided into two types: cell differentiation and neurotrophic factor secretion. These stem cells directly replace the damaged vascular cells through migration and differentiation after crossing the BBB. Several types of mononuclear cells (MNCs), including CD34 ${ }^{+}$, promote angiogenesis through their direct differentiation into smooth muscle cells (SMCs) and ECs in MCAO rats (Terry et al., 2011; Wang J. et al., 2013). In addition to the promotion of angiogenesis, the administration of endothelial progenitor cells (EPCs) seems to be effective in BBB renovation due to their vascular phenotype (Moubarik et al., 2011). The extensive vascular engraftment of human bone marrow EPCs (hBMEPCs) pre-labeled with $\beta$-gal suggests a necessary mechanism of direct differentiation for BBB repair (Garbuzova-Davis et al., 2017). MSC differentiation into ECs mediated by the Notch signaling pathway and mitochondrial nanotube transportation are other vital mechanisms of angiogenesis (Zhu et al., 2015). However, the differentiation of grafted stem cells into cells such SMCs or ECs is limited. The existence of direct differentiation has not been confirmed in either HSCs or other stem cell types (Uemura et al., 2012).

The bystander effect exerts a more comprehensive and effective influence in promoting angiogenesis and BBB preservation. Coordinated remodeling of ECs, basal matrix, and pericytes induces angiogenesis to produce new blood vessels 


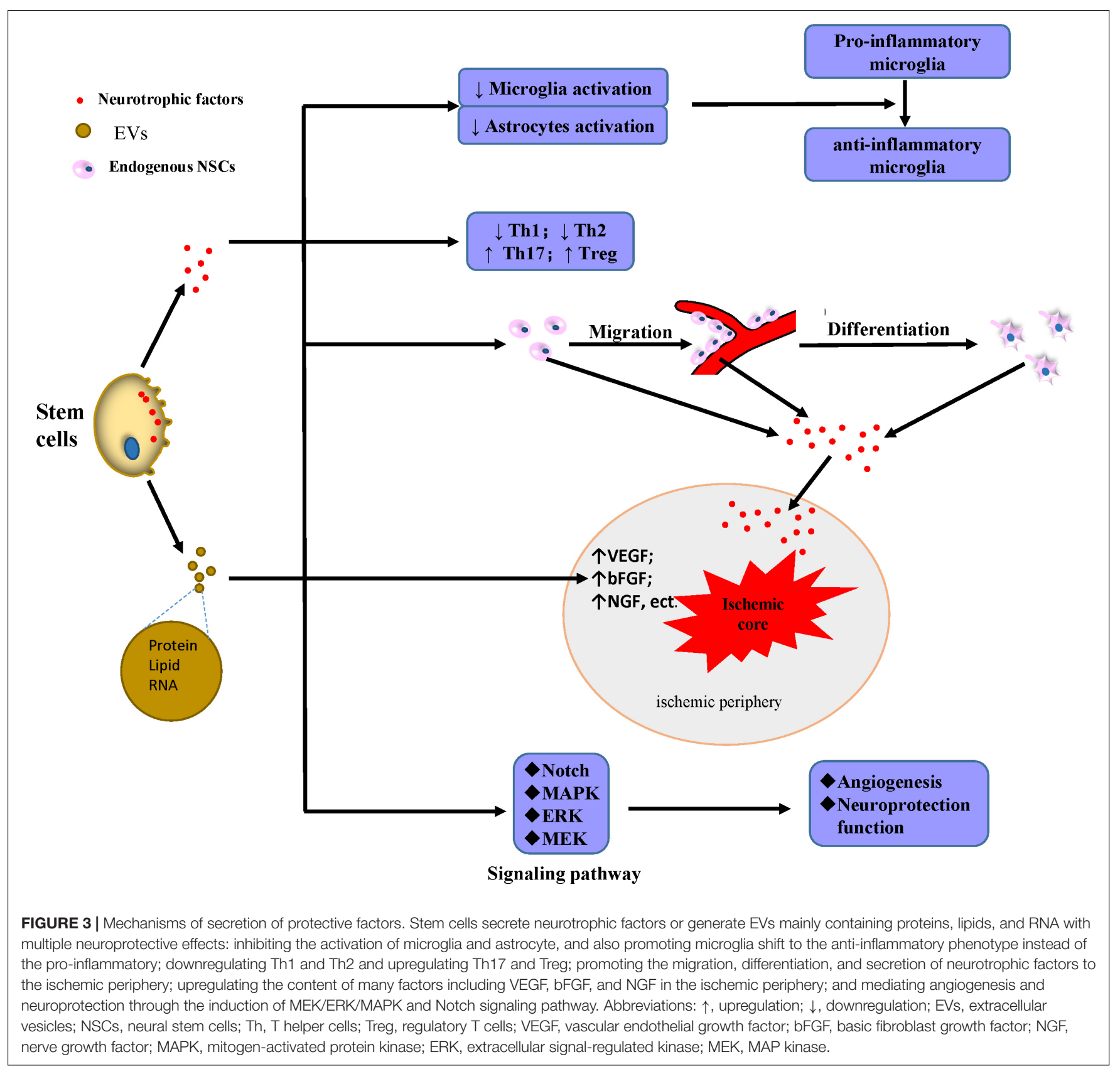

(Li and Carmeliet, 2018). This complex process is regulated by a variety of cytokines and receptors; and some mediators such as VEGF and TGF- $\beta$ modulate angiogenesis during the natural pathophysiological process (Kanazawa et al., 2019). VEGF, which has been widely studied in the transplantation of MNCs and MSCs, is able to promote angiogenesis by the bystander effect. The expression of other trophic factors such as BDNF, GDNF, Angiotensin 1 (Ang-1), Angiotensin 2 (Ang-2), IGF-1, and bFGF is upregulated after MNC treatment, contributing to the formation of immature vessels (Ikegame et al., 2011; Li et al., 2020b). Most of these cytokines promote angiogenesis by binding to specific receptors. For example, VEGF binding to VEGF receptor-2 (VEGFR-2) with high tyrosine-kinase activity improves angiogenesis, while binding to another receptor such as VEGFR-1 results in no protective effect. Some studies have shown that VEGFR-2 increases with VEGF upregulation after stem cell therapy in ischemic rats and that the same pattern was also observed in Ang-1 and its receptor Tie2 (Zacharek et al., 2007; Toyama et al., 2009). The angiogenic effect of VEGF in IS also varies according to the time window, source, and administration mode. Early administration of recombinant human VEGF in ischemic rats can significantly aggravate BBB leakage and hemorrhagic transformation (Zhang et al., 2000). The regulation of nutritional factors in the molecular mechanism of angiogenesis is multifaceted and often associated with neurogenesis (Hatakeyama et al., 2020a). A recent study 
found that autophagy may be a cause of vascular injury and that EVs secreted from MSCs can activate signal transduction and the activation of the transcription factor STAT3 to inhibit the autophagy-related pathway (Xia et al., 2020).

There has been a recent increase in miRNA research, and EVs containing certain miRNAs produce protective effects in stem cells through the activation of signaling pathways related to angiogenesis and neurogenesis (Bang and Kim, 2019; Moon et al., 2019). ADSCs in vitro secrete miRNA-181b, which promotes the angiogenesis in brain microvascular ECs through the transient receptor potential melastatin 7 (TRPM7) axis (Yang et al., 2018). MiRNAs can also regulate stem cell function; for example, miR-126 overexpression can promote the proliferation, migration, and tube formation abilities of EPCs and also the increase NO production of EPCs via activation of the PI3K/Akt/eNOS pathway, thus increasing cerebral microvascular density and angiogenesis (Pan et al., 2018). Angiogenesis is considered to be helpful for neurogenesis and the formation of neurovascular units and is favorable for regeneration and functional recovery of neurons.

\section{Neural Circuit Reconstruction}

Cells with different properties and functions in the brain form neural circuits and neural networks at different levels through various complex connections; and positive and negative feedback regulates the complex functions of the brain (Helmstaedter, 2013). IS results in the loss of brain neurons and the destruction of nerve connections, leading to severe neurological dysfunctions. Adult mammals have limited brain regeneration abilities (Li et al., 2020b), meaning that stem cell therapy can play an important role in the repair and functional reconstruction of damaged neural circuits.

Neurogenesis involves the generation of new functional neurons from NSCs, which includes their proliferation, migration, and differentiation into mature neurons. In the adult brain, endogenous neurogenesis continuously persists in two areas, the SVZ of the lateral ventricle and the subgranular zone (SGZ) of the hippocampus; and it increases after IS (Hatakeyama et al., 2020b). Several signaling pathways and extracellular factors are involved in the regulation of neurogenesis, which is further enhanced by stem cell treatment (Hatakeyama et al., 2020a,b). The activation of NSCs proliferation is regulated by Notch-mediated signaling and other transcription factors such as Wnt and the Sonic Hedgehog signaling pathway (Faigle and Song, 2013). The proliferation of endogenous NSCs can be enhanced by several extracellular factors such as FGF-2, IGF-1, and platelet-derived growth factor (PDGF) (Hatakeyama et al., 2020a), all of which are abundantly secreted by transplanted stem cells. Following NSC proliferation, several mechanisms mediated by the administered stem cells promote neuroblast migration from the SVZ to the peri-infarcted region, especially where angiogenesis occurs (Ruan et al., 2015). BDNF secreted by ECs promotes vascular-guided NSC migration (Grade et al., 2013). In newborn capillaries working as a scaffold, $\beta 1$ integrin expressed in neuroblasts can adhere to laminin expressed in the vessels to achieve migration (Grade et al., 2013). MSC treatment promotes NSC migration after the release of neurotrophic factors beneficial to angiogenesis. After proliferation and migration, NSCs differentiate into different mature neurons according to the local microenvironment in which they are located to repair damaged brain areas (Kawabori et al., 2020a). Angiogenesis plays a crucial role in the differentiation of NSCs into mature neurons in the ischemic area, as observed in in vitro experiments (Shen et al., 2004) and also in a recent animal study reporting that angiogenesis in the cortex can induce NSC transition from a proliferative form to a differentiated one (Shen et al., 2004). Transplanted stem cells can also perform neurogenesis by directly differentiating into neuronal cells. More than 50\% of transplanted stem cells in the ischemic brain express a neuronal phenotype at 2 months after cell transplantation (Kawabori et al., 2012, 2013).

The sprouting of axons increases the connections between different areas of the brain; however, in the adult brain after IS, axonal sprouting is limited by the failure of neurogenesis to be fully activated and by inhibitory cytokines (Carmichael et al., 2017). Treatment with stem cells such as MSCs, NSCs, and bone marrow-derived stem cells (BMCs) ameliorates this defect by promoting angiogenesis and bystander effects (Neuhuber et al., 2005; Fujioka et al., 2017; Huang et al., 2019). VEGF released from vessels, and laminin/ $\beta 1$ integrin signal in ECs induced by microtubule assembly and stabilization are both crucial aspects in promoting axonal outgrowth (Jin et al., 2006; Fujioka et al., 2017). Since axonal sprouting is limited before angiogenesis, this suggests a close connection between axonal sprouting and angiogenesis (Kanazawa et al., 2017a). Treatment with BDNF, gene-transfected MSCs, and axonal outgrowth can also be promoted (Hira et al., 2018).

Synaptogenesis is a long back-and-forth process involving synapse formation, synapse stabilization, and activity-dependent synapse refinement and elimination, all important aspects to maintain the stability and precision of neural circuits (Cepeda et al., 2002). Research on synaptogenesis after stem cell therapy is currently focused on the changes in characteristics. Following treatment with reprogrammed human neural precursor cells derived from iPSCs, the increased expression of the presynaptic vesicle protein synaptophysin enhances synaptogenesis after IS (Vonderwalde et al., 2020). Another study demonstrated that stem cell factor and G-CSF may promote synaptogenesis through VEGF- $\alpha$ (Ping et al., 2019).

Stem cell therapy mechanisms can be categorized into two distinct forms: direct action characterized by cell migrating to the infarct area and bystander effort, and indirect action characterized by improving local microenvironment through angiogenesis, neurogenesis, and the regulation of inflammation. Both mechanisms can combine to improve neuronal function after IS; however, the different mechanisms do not receive the same level of focus in the current research. There has been a lot of fundamental research into exosomes and their related secreted factors, as a medium for information exchange between cells, in stem cell therapy. However, there is limited research on direct differentiation of stem cells, which may be related to the current lack of effective detection methods. The examination of new key molecules or regulatory pathways 
that regulate indirect action should also be encouraged, as these mechanisms are part of a closely connected network. For example, neuroinflammation reduction can be assisted by the alleviation of inflammatory factor infiltration when the BBB is repaired, and the regulation of inflammation provides a favorable microenvironment for angiogenesis or neurogenesis, which in turn supplies oxygen and nutrients to ischemic tissue and neurotrophic factor necessary for axonal outgrowth. Stem cell therapy, through the regulation of multiple mechanisms, is an innovative treatment with outstanding advantages (Figure 4).

\section{CLINICAL STEM CELL THERAPY TRIALS}

Over the last decades, a large number of preclinical studies have been carried out on the role of stem cell therapy in IS treatment. Thanks to the promising results of the preclinical studies, an increasing number of clinical trials have investigated the safety and efficacy of different stem cells in IS treatment. Some issues still need to be resolved, such as the choice of the cell type, cell dose, time of transplantation, and injection routes, all of which benefit from a close link between basic and clinical research (Table 1).

\section{Choice of Stem Cell Types}

Several types of stem cells have been widely studied in IS animal models, and some of them have been examined in clinical trials. All the stem cells used play important roles in the treatment of IS through different mechanisms. Stem cells can be obtained from different tissues of the same IS patient, including bone marrow, adipose tissue, dental pulp, and connective tissue; or they can be commercially purchased. Although several clinical studies have investigated the safety and effectiveness of some stem cells, more attention has focused on BMCs such as MSCs (Steinberg et al., 2018). Tissue-derived MSCs remain the main cells used in stem cell therapy to treat IS because of their easy access and different protective mechanisms; however, the choice of a proper stem cell type in clinical IS treatment should take into account not only the advantages mentioned above but also the accessibility, ethical issues, risk of posttransplant rejection, allergies, and even tumorigenicity. When there is a high risk of posttransplant rejection, autologous stem cells are more suitable (Bang et al., 2005a; Chen D.C. et al., 2014; Trounson and McDonald, 2015). However, since IS is an acute disease, the time required to culture some autologous stem cells, such as BM-MSCs to reach the number required for transplantation, limits their application in acute phase of IS, and allogeneic stem
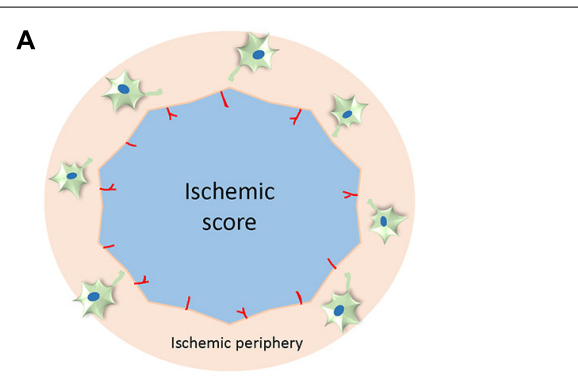

Cerebral ischemia without treatment

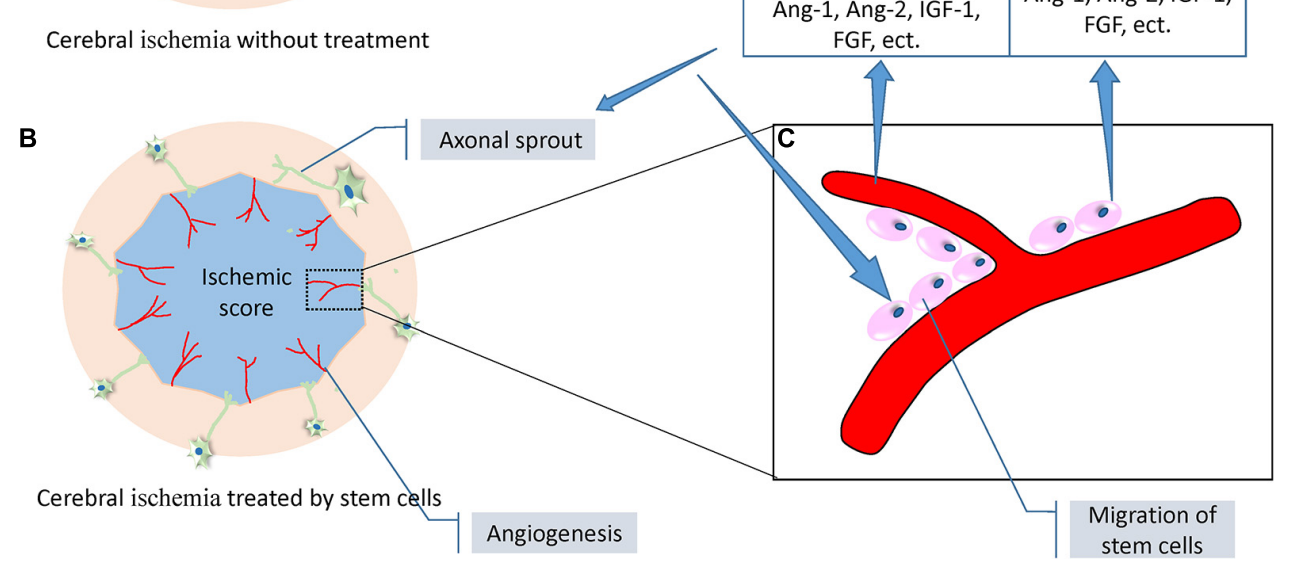

FIGURE 4 | A set of diagrams of angiogenesis, neurogenesis, and axonal outgrowth under the treatment of stem cells following ischemic stroke (modified from the reference of Masato Kanazawa et al., 2019). (A) A proposed diagram depicting the location of angiogenesis and axonal outgrowth after ischemic stroke without intervention. Weak angiogenesis (red lines) occurs at the border of the ischemic core (blue) and peripheral areas, and limited axonal sprouting occurs in the neurons (green cells) of the peripheral areas. (B) A proposed diagram depicting enhanced angiogenesis and evident axonal sprouting and outgrowth under the treatment of stem cells. (C) A representative diagram expanded from a certain area of the diagram in (B). Stem cells (pink) adhering to the newly formed blood vessels to achieve migration. The blood vessels and stem cells themselves secrete a variety of neurotrophic factors including VEGF, BDNF, GDNF, Ang-1, Ang-2, IGF-1, and FGF. In addition, blood vessels release additional oxygen and nutrients to promote the proliferation, migration, and differentiation of stem cells, and axonal outgrowth. Abbreviations: VEGF, vascular endothelial growth factor; BDNF, brain-derived neurotrophic factor; GDNF, glial cell-derived neurotrophic factor; Ang-1, angiotensin 1; Ang-2, angiotensin 2; IGF-1, insulin-like growth factor 1; FGF, fibroblast growth factor. 
TABLE 1 | Summary of stem cells administered in clinical trials.

\begin{tabular}{|c|c|c|c|c|c|}
\hline Stem cell types & Routes & Timing & Dose & Outcome & References \\
\hline MSCs & Intracerebral & $\begin{array}{l}\text { Subacute } \\
\text { phase }\end{array}$ & $2.5-10 \times 10^{6}$ & $\begin{array}{l}\text { No adverse events, and dose-limiting toxicity or death and } \\
\text { improved clinical outcomes. }\end{array}$ & $\begin{array}{l}\text { Steinberg et al., } \\
2018\end{array}$ \\
\hline MSCs & Intravenous & $\begin{array}{l}\text { Subacute } \\
\text { phase }\end{array}$ & $0.6-1.5 \times 10^{8}$ & $\begin{array}{l}\text { Reduced lesion volume as demonstrated by MRI and functional } \\
\text { recovery with no tumor or abnormal cell growth. }\end{array}$ & $\begin{array}{l}\text { Honmou et al., } \\
2011\end{array}$ \\
\hline MSCs & Intravenous & Chronic phase & $1.5 \times 10^{6} / \mathrm{kg}$ & $\begin{array}{l}\text { Safety and improvements were seen in the National Institutes of } \\
\text { Health Stroke Scale, Barthel Index, Mini-Mental Status Exam, and } \\
\text { Geriatric Depression Scale scores during the follow-up study. }\end{array}$ & Levy et al., 2019 \\
\hline MSCs & Intravenous & Acute phase & $1 \times 10^{6} / \mathrm{kg}$ & $\begin{array}{l}\text { No adverse events, neurologic and systemic complications, and } \\
\text { tumor development and improved neurologic recovery with } \\
\text { decreased infarct size. }\end{array}$ & $\begin{array}{l}\text { Díez-Tejedor et al., } \\
2014\end{array}$ \\
\hline MSCs & Intravenous & $\begin{array}{l}\text { Subacute } \\
\text { phase }\end{array}$ & $2.875 \times 10^{9}$ & $\begin{array}{l}\text { No significant difference between the BMSC arm and control arm in } \\
\text { the Barthel Index score, Modified Rankin Scale shift analysis, } \\
\text { National Institutes of Health Stroke Scale, and infarct volume. }\end{array}$ & Prasad et al., 2014 \\
\hline HSCs & Intra-arterial & Acute phase & $1 \times 10^{8}$ & $\begin{array}{l}\text { Improvements in the Modified Rankin Scale score and National } \\
\text { Institutes of Health Stroke Scale score and reductions in lesion } \\
\text { volume during a 6-month follow-up period. }\end{array}$ & $\begin{array}{l}\text { Banerjee et al., } \\
\qquad 2014\end{array}$ \\
\hline HSCs & Intrathecal & Chronic phase & $0.8-3.3 \times 10^{7}$ & Improved muscle tone, rigidity, and motor power. & $\begin{array}{l}\text { Wang L. et al., } \\
\qquad 2013\end{array}$ \\
\hline NSCs & Intracerebral & Chronic phase & $2 \times 10^{6} / 5 \times 10^{6}$ & $\begin{array}{l}\text { No immunological or cell-related adverse events, decreased infarct } \\
\text { lesions observed by MRI. }\end{array}$ & $\begin{array}{l}\text { Kalladka et al., } \\
\qquad 2016\end{array}$ \\
\hline NSCs & Intracerebral & $\begin{array}{l}\text { Subacute to } \\
\text { chronic phases }\end{array}$ & $2 \times 10^{7}$ & $\begin{array}{l}4 \text { of } 23 \text { participants improved by the pre-specified Action Research } \\
\text { Arm Test subtest level; transient procedural adverse effects were } \\
\text { observed, but no stem cell-related adverse events. }\end{array}$ & Muir et al., 2020 \\
\hline DPSCs & Intracerebral & Chronic phase & $1 \times 10^{7}$ & Safe, feasible, and observed function recovery. & Nagpal et al., 2016 \\
\hline PBSCs & Intracerebral & Chronic phase & $3-8 \times 10^{6}$ & $\begin{array}{l}\text { No serious adverse events; improvements in the National Institutes } \\
\text { of Health Stroke Scale, Modified Rankin Scale, European Stroke } \\
\text { Scale (ESS), and ESS Motor Subscale from the baseline to the end } \\
\text { of the 12-month follow-up period. }\end{array}$ & $\begin{array}{l}\text { Chen D.C. et al., } \\
2014\end{array}$ \\
\hline MSCs & Intravenous & $\begin{array}{l}\text { Subacute } \\
\text { phase }\end{array}$ & $1 \times 10^{8}$ & $\begin{array}{l}\text { No adverse cell-related, serological, or imaging-defined effects, and } \\
\text { the Barthel index and Modified Rankin Scale score consistently } \\
\text { improved during the follow-up period with less prominent infarcted } \\
\text { areas. }\end{array}$ & Bang et al., 2005a \\
\hline BMMNCs & Intra-arterial & $\begin{array}{l}\text { Subacute } \\
\text { phase }\end{array}$ & $5 \times 10^{8}$ & $\begin{array}{l}\text { No procedure-related mortality, complications, new infarct, or } \\
\text { symptomatic intracranial hemorrhage and good clinical outcome } \\
\text { observed by Modified Rankin Scale score. }\end{array}$ & Bhatia et al., 2018 \\
\hline BMMNCs & Intravenous & Acute phase & $2.5 \times 10^{8} / 3.4 \times 10^{8}$ & $\begin{array}{l}\text { Improved cerebral blood flow and metabolic rate of oxygen } \\
\text { consumption } 6 \text { months after treatment with significantly better } \\
\text { neurologic outcomes. }\end{array}$ & Taguchi et al., 2015 \\
\hline BMMNCs & Intravenous & Acute phase & $1 \times 10^{7} / \mathrm{kg}$ & $\begin{array}{l}\text { No severe adverse events and diffusion tensor tractography } \\
\text { illustrates an increase in cortical spinal tracts fiber volume. }\end{array}$ & Vahidy et al., 2019 \\
\hline Fetus neuronal cell & Intracerebral & Chronic phase & $5 \times 10^{6}$ & $\begin{array}{l}\text { Safe and feasible but no evidence of significant benefit in motor } \\
\text { function were observed. }\end{array}$ & $\begin{array}{l}\text { Kondziolka et al., } \\
2005\end{array}$ \\
\hline Fetal porcine cells & Intracerebral & $\begin{array}{l}\text { Subacute to } \\
\text { chronic phase }\end{array}$ & $1 \times 10^{6}$ & $\begin{array}{l}\text { Temporary worsening of motor deficits and seizure; } 2 \text { of } 5 \text { patients } \\
\text { showed improvement in speech, language, and/or motor } \\
\text { impairments over several months and persisted at } 4 \text { years. The } \\
\text { study was terminated by the Food and Drug Administration. }\end{array}$ & Savitz et al., 2005 \\
\hline
\end{tabular}

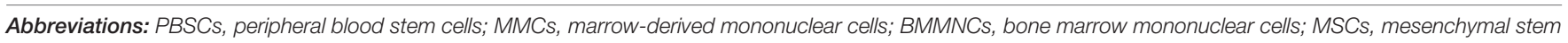
cells; HSCs, hematopoietic stem cells; DPSCs, dental pulp stem cells; NSCs, neural stem cells.

cells are therefore usually selected. In a phase I safety study, the fourth injection of allogeneic human UCB cells proved to be safe in adults with IS, and patient recovery was improved (Laskowitz et al., 2018). Although allogeneic stem cells have promising prospects, some issues still need to be solved, including the lack of systems guaranteeing the standard quality of stem cells administered in clinical trials or treatments, and the expense of producing, preserving, and transferring these cells. Although most methods used for stem cell therapy appear to be safe, some studies have reported on the continuous limitations in the administration of some stem cells such as ESC and iPSCs because of the risk of tumorigenicity, immunogenicity, and heterogeneity (Yamanaka, 2020). The transplantation of iPSCs can increase the risk of teratoma, especially in IS models (Yamashita et al., 2011), suggesting that the safety of stem cells should be evaluated. On the other hand, several studies have obtained encouraging results using ESC and iPSC; thus, the confidence of using them in clinical treatments is increased. The organ-on-a-chip model, 
which is a sensitive in vitro system, is being developed to effectively predict the possibility of tumor formation (Sato et al., 2019). There are many mechanisms characterizing the underlying therapeutic effect of stem cells, meaning that one of them may be making the main contribution. For example, the bystander effect in MSCs after IS can effectively improve functional recovery, NSCs possess a strong ability to differentiate into neurons and reconstruct the neural circuit, and HSCs can significantly stimulate angiogenesis, which ameliorates OGD damage. The self-renewal and differentiation abilities of stem cells greatly differ. During IS, the pathophysiological changes after stroke are due to a dynamic process, which in turn requires a flexibility in stem cell choice dependent on individual patient's conditions. In the acute phase of IS, the main danger can be the acute cascade of neuroinflammatory factors, damage of the $\mathrm{BBB}$, and the apoptosis of CNS cells, while sustained neuroinflammation, the formation of glial scar, and the destruction of the neural circuit influence the functional recovery in the subacute to chronic phase. MSC administration can significantly reduce the volume of the ischemia lesion and increase the functional recovery with the improvement of the outcome of the Modified Rankin Scale (mRS) and National Institutes of Health Stroke Scale (NIHSS) (Honmou et al., 2011; Díez-Tejedor et al., 2014). The paracrine effect of MSCs contributes, at least in part, to this neuroprotective effect. The safety of HSCs therapy is proven (Wang L. et al., 2013), and it can significantly improve the functional outcome from the baseline to the end of the 12-month follow-up period (Chen D.C. et al., 2014). Based on the different features of stem cell types and the pathophysiological change in each phase of IS, it is advisable that the stem cell therapeutic strategy should be adjusted to the pathophysiology features according to further clinical studies.

\section{Stem Cell Administration Routes}

Different administration routes including intravenous, intra-arterial, intrathecal, intracerebroventricular, intracerebral, subarachnoid, intranasal, and intraperitoneal routes have been used in preclinical trials, and many clinical studies have reported on the safety of these administration routes. The intravenous and intracerebral routes are widely used in published clinical studies; however, it is not clear which of them represents the optimal route.

The intra-arterial route is less invasive than the others. Like the intravenous route, the intra-arterial route can be used with a large number of cells (Bang et al., 2005b; Savitz et al., 2011b); however, the advantage of the intra-arterial route is that stem cells can bypass the peripheral filtering organs such as the liver, the spleen, and the lungs, leading to a higher cell engraftment into the brain and biological distribution (Berkhemer et al., 2015). A study using stem cells transduced with a firefly luciferase reporter gene for bioluminescence imaging (BLI) revealed that the BLI signal in the brain of the rats treated with the intraarterial route is significantly higher than that in the lungs and liver and is higher than the signal in the brain after intravenous injection (Pendharkar et al., 2010). The MT is widely used at 3$4.5 \mathrm{~h}$ after IS with the help of a catheter (Wardlaw et al., 2014), and it is worth considering the combination of this and the intraarterial route for the delivery of stem cells into the ischemic lesion. However, there is still the risk that the stem cells can stick together and form microemboli, blocking the vasculature and leading to occlusions and local hypoperfusion (Walczak et al., 2008). The intravenous route and intra-arterial route show the same protective features or feasibility, but the intravenous route is the one mainly used in recently published studies because of repeatability, lower invasiveness, easy access, and inessentiality of special equipment such as catheters. The intravenous route greatly contributes to the amelioration of neuroinflammation, activation of immune cells, and neuron apoptosis thanks to the stem cells' secretion of neurotrophic factors to modulate neuroinflammation or immune response. The transplanted stem cells administered by intravenous injection go over the pulmonary vascular system arriving in the infarcted area in IS (Misra et al., 2012); however, a large proportion of transplanted stem cells are trapped in the peripheral organs (Kawabori et al., 2012; Boltze et al., 2015). Interestingly, the stem cells trapped in the spleen improve the splenic inflammatory response, reduce neuron apoptosis in the brain, and increase the functional recovery (Vasconcelos-dos-Santos et al., 2012; Huang et al., 2013; Acosta et al., 2015). Like the stem cells transplanted by the intra-arterial routes, stem cells transplanted by the intravenous one can also lead to the formation of microemboli causing fatal pulmonary embolism. Nevertheless, the intravascular routes (intravenous and intra-arterial route) mainly contribute to the functional recovery that may mainly rely on the bystander effect, while the intrathecal, intracerebroventricular, intracerebral, and subarachnoid routes are invasive routes that can directly deliver the stem cell into the CNS, thus facilitating the reconstruction of the neural circuit and the replacement of the damaged brain tissues in IS (Kelly et al., 2004). After IS, stem cell transplantation through the intracerebral route resulted in more transplanted stem cells appearing near the infarcted lesions because of the direct injection of millions of stem cells under the help of invasive surgery. Approximately $1 / 3$ can migrate to the ischemic area (Darsalia et al., 2007; De Feo et al., 2012), thus achieving the highest stem cell engraftment of all administration routes. However, invasive surgery can bring a second attack to the patient, and intracerebral routes are predominantly used in the chronic phase of IS, according to published clinical studies (Kondziolka et al., 2005; Chen et al., 2013; Steinberg et al., 2016; Steinberg et al., 2018). The amount of transplanted stem cells is limited to avoid the mass effect, and the harsh microenvironment containing inflammatory factors can influence the grafted stem cells survival, differentiation, proliferation, and migration (Bühnemann et al., 2006). The risk of additional brain damage caused by injection needles and invasive surgery-related complications including death, seizure, and infection should be taken into consideration (Jeong et al., 2014; Kawabori et al., 2020b). The intracerebroventricular route may be less invasive than the intracerebral route, but complications such as hydrocephalus and liquorrhea may occur after administration. Recently, a novel delivery route for stem cells for IS therapy has been reported and gained attention because of its effectiveness and minimal invasiveness. Indeed, the 
intranasal administration of cells allows the bypass of the BBB and increases the migration into the lesions (Wei et al., 2013, 2015), and MSCs administered through this route show great potential to enhance neurovascular regeneration and improve functional recovery (Wei et al., 2015). However, the intranasal and intraperitoneal routes are still at the stage of preclinical studies and need further safety and efficacy evaluation before use in large-scale clinical trials. So far, the strong connection between routes of administration and the target of stem cell therapy is quite evident. In the acute phase of IS, the neuroinflammation and neural cell death greatly contribute to the ischemia damage to the CNS, and at present, the intravascular routes are preferable in order to use the bystander effect. However, in the chronic phase of IS, when the acute pathophysiology changes are stabilized, the replacement of the damaged tissue can be more important, and intracerebral or other invasive routes are more proper to directly enhance cellular intercommunication. Nevertheless, many issues still exist, which should be taken into consideration when deciding the optimal choice of administration routes.

\section{Time of Administration}

Nowadays, not all patients are eligible for reperfusion treatment because of the narrow time window, although MT and the administration of tPA are widely used in clinical practice. In the different phases of IS such as acute, subacute, and chronic phases, many pathophysiological changes occur. However, some particular pathophysiological changes play major roles in different phases, enabling us to consider specific treatments. Based on the pathophysiology features of different IS phases, treatment strategies regarding the administration time have been discussed in clinical and preclinical studies. In acute or subacute phases of IS, a series of cytokines, chemokines, and reactive oxygen species are released, which change the microenvironment, finally damaging the neural cells (Choi, 1992; Adibhatla and Hatcher, 2010; Dabrowska et al., 2019a; Jayaraj et al., 2019), although some of these factors have positive effects. For example, the release of some chemokines including SDF after the onset of IS can induce the migration of exogenous transplanted stem cells (Chen Y. et al., 2014). Administration of stem cells in the early phases of IS can reduce neuroinflammation, modulate the immune system, regulate the microenvironment, and rescue neurons and glial cells in the peri-ischemia areas (Bang, 2016), suggesting that the focus of cell therapy in the acute and subacute phases should be on the rescue of ischemia-damaged cells (Savitz et al., 2011a). In the rat IS model, the administration of NSCs shortly after stroke $(48 \mathrm{~h})$ results in a better stem cell survival compared with stem cells administered 6 weeks after stroke. The same study also reported that the activation of microglia after the onset of IS reaches the maximum level at 1 to 6 weeks after stroke (Darsalia et al., 2011), suggesting that the administration of stem cells before the total establishment of neuroinflammation increases the survival of stem cells and improves their therapeutic effect. Thus, according to the instruction of preclinical studies, some clinical trials reported the safety and efficacy of stem cell administration in an early phase of IS (Kim et al., 2013; Shichinohe et al., 2017; Bhatia et al., 2018), resulting in a good clinical outcome, since $80 \%$ of the patients who received stem cell administration in the early phase of IS show good functional recovery (Bhatia et al., 2018). The early phase of IS is the appropriate period for traditional reperfusion treatment and stem cell therapy as well, but functional recovery in this phase is influenced by many factors including the spontaneous recovery of endogenous angiogenesis or neurogenesis. It is therefore important to take these aspects into consideration when assessing the effect of stem cell therapy in future clinical studies. The purpose of stem cell therapy in the chronic phase is totally different because it focuses mainly on neurogenesis, angiogenesis, and synaptic plasticity in peri-ischemic areas to restore neuronal functions. Trials in this phase mainly transplant the stem cells into peri-infarcted areas, promoting intercommunication between exogenous stem cells and cells that survived in the CNS, which increases the reconstruction of the neural circuit (Kalladka et al., 2016). Some clinical trials have reported the efficacy of stem cell therapy in the chronic phase of IS by intracerebral and intravascular routes (Chen D.C. et al., 2014; Levy et al., 2019; Muir et al., 2020). However, the study was interrupted because of a temporary worsening of the motor deficits and seizures when stem cells were administered in the chronic phase (Savitz et al., 2005). Therefore, the limited efficiency to replace the damaged tissue in the chronic phase of IS should be taken into consideration because of the formation of glial scar, irremediable loss of amount of brain parenchyma, and lack of blood supply to the transplanted stem cells (Colton, 1995; Diotel et al., 2020). Despite these negative aspects, tissue engineering hopes to solve the problems of administering stem cells in the chronic phase of IS. Some artificial scaffolds and matrix can serve as a platform to provide niches that can increase survival, proliferation, and functions of the transplanted stem cells (Murphy et al., 2010; Gopalakrishnan et al., 2019), thus solving the problems mentioned above, although the effect of stem cell therapy in the chronic phase of stroke still needs more research.

\section{Cell Dose}

The stem cell dose is flexible but should be adapted to the particular cell type or transplantation route used. The cell dose applied in clinical trials can widely differ from $10^{6}$ to $10^{9}$. Considering the easy access and the lowest invasiveness of the intravenous or intra-arterial routes, the cell dose can reach more than $10^{8}$ (Taguchi et al., 2015; Hess et al., 2017; Bhatia et al., 2018; Levy et al., 2019; Vahidy et al., 2019). For example, the number of transplanted stem cells by intravenous route can reach 1,200 million, with no dose-limiting toxicity events, allergic reactions, and treatment-emergent adverse events, revealing the safety of such cell dose (Hess et al., 2017). A recent study used two different cell doses $\left(10^{5}\right.$ and $\left.10^{6}\right)$ of MSCs that were intravenously administered. Although both doses improved functional recovery, the result revealed higher stem cell engraftment in the peri-infarct area at the higher dose, suggesting that the therapeutic effect of stem cells is positively correlated with the cell dose in a proper range (Kawabori et al., 2013). A meta-analysis regarding the relationship between the therapeutic effect and dose of transplanted stem cells did not 
show a significant linear regression relationship between them (Wang et al., 2016). Since a higher stem cell number can lead to the mass effect when administered by intracerebral route, the transplantation dose should be limited to no more than $10^{7}$ (Kalladka et al., 2016, 2019; Nagpal et al., 2016; Muir et al., 2020). A heterogeneous functional outcome is still observed under the same cell dose administered by the intracerebral route, probably because of patients in different conditions and the influence of a particular microenvironment. Some studies on material technology give hope on the use of several engineered matrix such as a hyaluronic acid (HA)-based self-polymerizing hydrogel that can serve as a platform for transplanted stem cells, miming the native neural tissue environment, and minimizing the influence from the environment of the peri-ischemia area after transplantation into the stroke core. This improves the survival and migration of stem cells, finally differentially modulating the transplanted cell fate (Moshayedi et al., 2016; Gopalakrishnan et al., 2019). Administration of the engineered matrix can significantly increase the implantation efficiency and can influence the transplantation dose as well. Only few studies are available discussing the appropriate cell dose in stem cell therapy and considering the risk of formation of tumors and thrombosis, and thus, further studies should investigate these issues before the widespread use of stem cell therapy in clinical practice.

\section{CONCLUSION}

Our review summarizes the mechanisms of stem cell therapy in detail, as well as several key parameters elucidated by the

\section{REFERENCES}

Abe, T., Aburakawa, D., Niizuma, K., Iwabuchi, N., Kajitani, T., Wakao, S., et al. (2020). Intravenously transplanted human multilineage-differentiating stressenduring cells afford brain repair in a mouse lacunar stroke model. Stroke 51, 601-611. doi: 10.1161/strokeaha.119.026589

Acosta, S. A., Tajiri, N., Hoover, J., Kaneko, Y., and Borlongan, C. V. (2015). Intravenous bone marrow stem cell grafts preferentially migrate to spleen and abrogate chronic inflammation in stroke. Stroke 46, 2616-2627. doi: 10.1161/ strokeaha.115.009854

Adibhatla, R., and Hatcher, J. (2010). Lipid oxidation and peroxidation in CNS health and disease: from molecular mechanisms to therapeutic opportunities. Antioxid. Redox Signal. 12, 125-169. doi: 10.1089/ars.2009.2668

Alishahi, M., Farzaneh, M., Ghaedrahmati, F., Nejabatdoust, A., Sarkaki, A., and Khoshnam, S. (2019). NLRP3 inflammasome in ischemic stroke: as possible therapeutic target. Int. J. Stroke 14, 574-591. doi: 10.1177/1747493019841242

Allegrucci, C., Wu, Y., Thurston, A., Denning, C., Priddle, H., Mummery, C., et al. (2007). Restriction landmark genome scanning identifies culture-induced DNA methylation instability in the human embryonic stem cell epigenome. Hum. Mol. Genet. 16, 1253-1268. doi: 10.1093/hmg/ddm074

Ao, L. Y., Yan, Y. Y., Zhou, L., Li, C. Y., Li, W. T., Fang, W. R., et al. (2018). Immune cells after ischemic stroke onset: roles, migration, and target intervention. J. Mol. Neurosci. 66, 342-355. doi: 10.1007/s12031-018-1173-4

Asgari Taei, A., Dargahi, L., Nasoohi, S., Hassanzadeh, G., Kadivar, M., and Farahmandfar, M. (2020). The conditioned medium of human embryonic stem cell-derived mesenchymal stem cells alleviates neurological deficits and improves synaptic recovery in experimental stroke. J. Cell. Physiol. 236, 19671979. doi: $10.1002 /$ jcp. 29981 current clinical research, providing a reference and a guide in the direction of further research. Stem cell therapy is a promising treatment strategy to cure IS, with multi-mechanisms that can effectively cope with the pathophysiological changes after stroke. In addition, many preclinical and clinical trials have revealed promising prospects in the administration of stem cell therapy to cure IS. However, much research still needs to be performed, and new discoveries may help develop a better use or modification of stem cell therapy or the treatment methods derived from it. Current clinical trials are still mainly in phase I of safety. The next step may require exploration of more clinically suited issues, such as the choice of stem cell types, the route of stem cell administration, the administration time, and the cell dose. These still unclear aspects require results from double-blind studies with larger cohorts.

\section{AUTHOR CONTRIBUTIONS}

All the authors participated in analyzing and discussing the literature, commenting on and approving the manuscript. AS and LW supervised the research, led the discussion, and wrote and revised the manuscript. All authors read and approved the final manuscript.

\section{FUNDING}

This work was supported by the Zhejiang Provincial Natural Science Foundation of China (LY18H090007) and National Natural Science Foundation of China (81701144).

Bala, M., Celinska-Lowenhoff, M., Szot, W., Padjas, A., Kaczmarczyk, M., Swierz, M., et al. (2020). Antiplatelet and anticoagulant agents for secondary prevention of stroke and other thromboembolic events in people with antiphospholipid syndrome. Cochrane Database Syst. Rev. 10:CD012169. doi: 10.1002/14651858. CD012169.pub3

Banerjee, S., Bentley, P., Hamady, M., Marley, S., Davis, J., Shlebak, A., et al. (2014). Intra-arterial immunoselected CD34+ stem cells for acute ischemic stroke. Stem Cells Transl. Med. 3, 1322-1330. doi: 10.5966/sctm.20130178

Bang, O., and Kim, E. H. (2019). Mesenchymal stem cell-derived extracellular vesicle therapy for stroke: challenges and progress. Front. Neurol. 10:211. doi: 10.3389/fneur.2019.00211

Bang, O., Lee, J., Lee, P., and Lee, G. (2005a). Autologous mesenchymal stem cell transplantation in stroke patients. Ann. Neurol. 57, 874-882. doi: 10.1002/ana. 20501

Bang, O. Y. (2016). Clinical trials of adult stem cell therapy in patients with ischemic stroke. J. Clin. Neurol. 12, 14-20.

Bang, O. Y., Lee, J. S., Lee, P. H., and Lee, G. (2005b). Autologous mesenchymal stem cell transplantation in stroke patients. Ann. Neurol. 57, 874-882. doi: 10.1002/ana.20501

Behzad-Behbahani, A., Pouransari, R., Tabei, S., Rahiminejad, M., Robati, M., Yaghobi, R., et al. (2005). Risk of viral transmission via bone marrow progenitor cells versus umbilical cord blood hematopoietic stem cells in bone marrow transplantation. Transplant. Proc. 37, 3211-3212. doi: 10.1016/j.transproceed. 2005.07.007

Benakis, C., Garcia-Bonilla, L., Iadecola, C., and Anrather, J. (2014). The role of microglia and myeloid immune cells in acute cerebral ischemia. Front. Cell. Neurosci. 8:461. doi: 10.3389/fncel.2014.00461 
Berkhemer, O., Fransen, P., Beumer, D., van den Berg, L., Lingsma, H., Yoo, A., et al. (2015). A randomized trial of intraarterial treatment for acute ischemic stroke. N. Engl. J. Med. 372, 11-20. doi: 10.1056/NEJMoa1411587

Bhatia, V., Gupta, V., Khurana, D., Sharma, R. R., and Khandelwal, N. (2018). Randomized assessment of the safety and efficacy of intra-arterial infusion of autologous stem cells in subacute ischemic stroke. AJNR Am. J. Neuroradiol. 39, 899-904. doi: 10.3174/ajnr.A5586

Birbrair, A. (2017). Stem cell microenvironments and beyond. Adv. Exp. Med. Biol. 1041, 1-3. doi: 10.1007/978-3-319-69194-7_1

Block, M., Zecca, L., and Hong, J. (2007). Microglia-mediated neurotoxicity: uncovering the molecular mechanisms. Nat. Rev. Neurosci. 8, 57-69. doi: 10. 1038/nrn2038

Boese, A. C., Le, Q. E., Pham, D., Hamblin, M. H., and Lee, J. P. (2018). Neural stem cell therapy for subacute and chronic ischemic stroke. Stem Cell Res. Ther. 9:154. doi: 10.1186/s13287-018-0913-2

Boldrini, M., Fulmore, C. A., Tartt, A. N., Simeon, L. R., Pavlova, I., Poposka, V., et al. (2018). Human hippocampal neurogenesis persists throughout aging. Cell Stem Cell 22, 589-599.e585. doi: 10.1016/j.stem.2018.03.015

Boltze, J., Arnold, A., Walczak, P., Jolkkonen, J., Cui, L., and Wagner, D. C. (2015). The dark side of the force - constraints and complications of cell therapies for stroke. Front. Neurol. 6:155. doi: 10.3389/fneur.2015.00155

Borlongan, C., Glover, L., Tajiri, N., Kaneko, Y., and Freeman, T. B. (2011). The great migration of bone marrow-derived stem cells toward the ischemic brain: therapeutic implications for stroke and other neurological disorders. Prog. Neurobiol. 95, 213-228. doi: 10.1016/j.pneurobio.2011.08.005

Bühnemann, C., Scholz, A., Bernreuther, C., Malik, C. Y., Braun, H., Schachner, M., et al. (2006). Neuronal differentiation of transplanted embryonic stem cellderived precursors in stroke lesions of adult rats. Brain 129(Pt 12), 3238-3248. doi: 10.1093/brain/awl261

Carmichael, S. T., Kathirvelu, B., Schweppe, C. A., and Nie, E. H. (2017). Molecular, cellular and functional events in axonal sprouting after stroke. Exp. Neurol. 287(Pt 3), 384-394. doi: 10.1016/j.expneurol.2016.02.007

Cepeda, C., Crawford, C., Margulies, J., Watson, J., Levine, M., and Cohen, R. W. (2002). Enhanced epileptogenic susceptibility in a genetic model of reactive synaptogenesis: the spastic Han-Wistar rat. Dev. Neurosci. 24, 262-271. doi: $10.1159 / 000066740$

Ceradini, D. J., and Gurtner, G. C. (2005). Homing to hypoxia: HIF-1 as a mediator of progenitor cell recruitment to injured tissue. Trends Cardiovasc. Med. 15, 57-63. doi: 10.1016/j.tcm.2005.02.002

Chamorro, Á, Dirnagl, U., Urra, X., and Planas, A. (2016). Neuroprotection in acute stroke: targeting excitotoxicity, oxidative and nitrosative stress, and inflammation. Lancet. Neurol. 15, 869-881. doi: 10.1016/s1474-4422(16) 00114-9

Chen, D. C., Lin, S. Z., Fan, J. R., Lin, C. H., Lee, W., Lin, C. C., et al. (2014). Intracerebral implantation of autologous peripheral blood stem cells in stroke patients: a randomized phase II study. Cell Transplant. 23, 1599-1612. doi: 10.3727/096368914x678562

Chen, J., Li, Y., Wang, L., Zhang, Z., Lu, D., Lu, M., et al. (2001). Therapeutic benefit of intravenous administration of bone marrow stromal cells after cerebral ischemia in rats. Stroke 32, 1005-1011. doi: 10.1161/01.str.32.4.1005

Chen, L., Xi, H., Huang, H., Zhang, F., Liu, Y., Chen, D., et al. (2013). Multiple cell transplantation based on an intraparenchymal approach for patients with chronic phase stroke. Cell Transplant 22(Suppl. 1), S83-S91. doi: 10.3727/ $096368913 \times 672154$

Chen, Y., Wei, Y., Liu, J., and Zhang, H. (2014). Chemotactic responses of neural stem cells to SDF- $1 \alpha$ correlate closely with their differentiation status. J. Mol. Neurosci. 54, 219-233. doi: 10.1007/s12031-014-0279-6

Cheng, Z., Wang, L., Qu, M., Liang, H., Li, W., Li, Y., et al. (2018). Mesenchymal stem cells attenuate blood-brain barrier leakage after cerebral ischemia in mice. J. Neuroinflammation 15:135. doi: 10.1186/s12974-018-1153-1

Choi, D. (1992). Excitotoxic cell death. J. Neurobiol. 23, 1261-1276. doi: 10.1002/ neu. 480230915

Chun, S. Y., Soker, S., Jang, Y. J., Kwon, T. G., and Yoo, E. S. (2016). Differentiation of human dental pulp stem cells into dopaminergic neuron-like cells in vitro. J. Korean Med. Sci. 31, 171-177. doi: 10.3346/jkms.2016.31.2.171

Colton, C. K. (1995). Implantable biohybrid artificial organs. Cell Transplant. 4, 415-436. doi: 10.1016/0963-6897(95)00025-s
Crain, J., Nikodemova, M., and Watters, J. (2013). Microglia express distinct M1 and M2 phenotypic markers in the postnatal and adult central nervous system in male and female mice. J. Neurosci. Res. 91, 1143-1151. doi: 10.1002/jnr.23242

Dabrowska, S., Andrzejewska, A., Lukomska, B., and Janowski, M. (2019a). Neuroinflammation as a target for treatment of stroke using mesenchymal stem cells and extracellular vesicles. J. Neuroinflammation 16:178. doi: 10.1186/ s12974-019-1571-8

Dabrowska, S., Andrzejewska, A., Strzemecki, D., Muraca, M., Janowski, M., and Lukomska, B. (2019b). Human bone marrow mesenchymal stem cell-derived extracellular vesicles attenuate neuroinflammation evoked by focal brain injury in rats. J. Neuroinflammation 16:216. doi: 10.1186/s12974-019-1602-5

Dailey, T., Metcalf, C., Mosley, Y. I., Sullivan, R., Shinozuka, K., Tajiri, N., et al. (2013). An Update on translating stem cell therapy for stroke from bench to bedside. J. Clin. Med. 2, 220-241. doi: 10.3390/jcm2040220

Damasceno, P., de Santana, T., Santos, G., Orge, I., Silva, D., Albuquerque, J., et al. (2020). Genetic engineering as a strategy to improve the therapeutic efficacy of mesenchymal stem/stromal cells in regenerative medicine. Front. Cell Dev. Biol. 8:737. doi: $10.3389 /$ fcell.2020.00737

Daneman, R., and Prat, A. (2015). The blood-brain barrier. Cold Spring Harb. Perspect. Biol. 7:a020412. doi: 10.1101/cshperspect.a020412

Darsalia, V., Allison, S. J., Cusulin, C., Monni, E., Kuzdas, D., Kallur, T., et al. (2011). Cell number and timing of transplantation determine survival of human neural stem cell grafts in stroke-damaged rat brain. J. Cereb. Blood Flow Metab. 31, 235-242. doi: 10.1038/jcbfm.2010.81

Darsalia, V., Kallur, T., and Kokaia, Z. (2007). Survival, migration and neuronal differentiation of human fetal striatal and cortical neural stem cells grafted in stroke-damaged rat striatum. Eur. J. Neurosci. 26, 605-614. doi: 10.1111/j.14609568.2007.05702.x

De Feo, D., Merlini, A., Laterza, C., and Martino, G. (2012). Neural stem cell transplantation in central nervous system disorders: from cell replacement to neuroprotection. Curr. Opin. Neurol. 25, 322-333. doi: 10.1097/WCO. 0b013e328352ec45

Del Rio, D., Stewart, A., and Pellegrini, N. (2005). A review of recent studies on malondialdehyde as toxic molecule and biological marker of oxidative stress. Nutr. Metab. Cardiovasc. Dis. 15, 316-328. doi: 10.1016/j.numecd.2005.05.003

Delcroix, G. J., Schiller, P. C., Benoit, J. P., and Montero-Menei, C. N. (2010). Adult cell therapy for brain neuronal damages and the role of tissue engineering. Biomaterials 31, 2105-2120. doi: 10.1016/j.biomaterials.2009.11.084

Demircan, P. C., Sariboyaci, A. E., Unal, Z. S., Gacar, G., Subasi, C., and Karaoz, E. (2011). Immunoregulatory effects of human dental pulp-derived stem cells on T cells: comparison of transwell co-culture and mixed lymphocyte reaction systems. Cytotherapy 13, 1205-1220. doi: 10.3109/14653249.2011.605351

Derakhshani, M., Abbaszadeh, H., Movassaghpour, A., Mehdizadeh, A., EbrahimiWarkiani, M., and Yousefi, M. (2019). Strategies for elevating hematopoietic stem cells expansion and engraftment capacity. Life Sci. 232:116598. doi: 10. 1016/j.lfs.2019.116598

Dezawa, M. (2016). Muse cells provide the pluripotency of mesenchymal stem cells: direct contribution of muse cells to tissue regeneration. Cell Transplant. 25, 849-861. doi: 10.3727/096368916x690881

Díez-Tejedor, E., Gutiérrez-Fernández, M., Martínez-Sánchez, P., RodríguezFrutos, B., Ruiz-Ares, G., Lara, M. L., et al. (2014). Reparative therapy for acute ischemic stroke with allogeneic mesenchymal stem cells from adipose tissue: a safety assessment: a phase II randomized, double-blind, placebo-controlled, single-center, pilot clinical trial. J. Stroke Cerebrovasc. Dis. 23, 2694-2700. doi: 10.1016/j.jstrokecerebrovasdis.2014.06.011

Diotel, N., Lübke, L., Strähle, U., and Rastegar, S. (2020). Common and distinct features of adult neurogenesis and regeneration in the telencephalon of zebrafish and mammals. Front. Neurosci. 14:568930. doi: 10.3389/fnins.2020. 568930

Drury-Stewart, D., Song, M., Mohamad, O., Guo, Y., Gu, X., Chen, D., et al. (2013). Highly efficient differentiation of neural precursors from human embryonic stem cells and benefits of transplantation after ischemic stroke in mice. Stem Cell Res. Ther. 4:93. doi: 10.1186/scrt292

Dudvarski Stankovic, N., Teodorczyk, M., Ploen, R., Zipp, F., and Schmidt, M. (2016). Microglia-blood vessel interactions: a double-edged sword in brain pathologies. Acta Neuropatholo. 131, 347-363. doi: 10.1007/s00401-0151524-y 
Eckert, A., Huang, L., Gonzalez, R., Kim, H. S., Hamblin, M. H., and Lee, J. P. (2015). Bystander effect fuels human induced pluripotent stem cell-derived neural stem cells to quickly attenuate early stage neurological deficits after stroke. Stem Cells Transl. Med. 4, 841-851. doi: 10.5966/sctm.2014-0184

Faigle, R., and Song, H. (2013). Signaling mechanisms regulating adult neural stem cells and neurogenesis. Biochim. Biophys. Acta 1830, 2435-2448. doi: 10.1016/j. bbagen.2012.09.002

Feigin, V., Nguyen, G., Cercy, K., Johnson, C., Alam, T., Parmar, P., et al. (2018). Global, regional, and country-specific lifetime risks of stroke, 1990 and 2016. N. Engl. J. Med. 379, 2429-2437. doi: 10.1056/NEJMoa1804492

Feigin, V. L., Abajobir, A. A., Abate, K. H., Abd-Allah, F., Abdulle, A. M., Abera, S. F., et al. (2017). Global, regional, and national burden of neurological disorders during 1990-2015: a systematic analysis for the Global Burden of Disease Study 2015. Lancet Neurol. 16, 877-897. doi: 10.1016/s1474-4422(17) 30299-5

Feng, Y., Yu, H. M., Shang, D. S., Fang, W. G., He, Z. Y., and Chen, Y. H. (2014). The involvement of CXCL11 in bone marrow-derived mesenchymal stem cell migration through human brain microvascular endothelial cells. Neurochem. Res. 39, 700-706. doi: 10.1007/s11064-014-1257-7

Foudah, D., Monfrini, M., Donzelli, E., Niada, S., Brini, A. T., Orciani, M., et al. (2014). Expression of neural markers by undifferentiated mesenchymal-like stem cells from different sources. J. Immunol. Res. 2014:987678. doi: 10.1155/ 2014/987678

Fujioka, T., Kaneko, N., Ajioka, I., Nakaguchi, K., Omata, T., Ohba, H., et al. (2017). $\beta 1$ integrin signaling promotes neuronal migration along vascular scaffolds in the post-stroke brain. EBioMedicine 16, 195-203. doi: 10.1016/j.ebiom.2017. 01.005

Garbuzova-Davis, S., Haller, E., Lin, R., and Borlongan, C. V. (2017). Intravenously transplanted human bone marrow endothelial progenitor cells engraft within brain capillaries, preserve mitochondrial morphology, and display pinocytotic activity toward blood-brain barrier repair in ischemic stroke rats. Stem Cells 35, 1246-1258. doi: 10.1002/stem.2578

Garcia, J., Liu, K., Yoshida, Y., Lian, J., Chen, S., and del Zoppo, G. (1994). Influx of leukocytes and platelets in an evolving brain infarct (Wistar rat). Am. J. Pathol. 144, 188-199.

GBD 2016 Stroke Collaborators (2019). Global, regional, and national burden of stroke, 1990-2016: a systematic analysis for the Global burden of disease study 2016. Lancet Neurol. 18, 439-458. doi: 10.1016/s1474-4422(19)30034-1

Geiseler, S., and Morland, C. (2018). The Janus face of VEGF in stroke. Int. J. Mol. Sci. 19, 1362. doi: 10.3390/ijms 19051362

Gelderblom, M., Weymar, A., Bernreuther, C., Velden, J., Arunachalam, P., Steinbach, K., et al. (2012). Neutralization of the IL-17 axis diminishes neutrophil invasion and protects from ischemic stroke. Blood 120, 3793-3802. doi: 10.1182/blood-2012-02-412726

Geng, W., Tang, H., Luo, S., Lv, Y., Liang, D., Kang, X., et al. (2019). Exosomes from miRNA-126-modified ADSCs promotes functional recovery after stroke in rats by improving neurogenesis and suppressing microglia activation. Am. J. Transl. Res. 11, 780-792.

Gimeno, M., Fuertes, F., Barcala Tabarrozzi, A., Attorressi, A., Cucchiani, R., Corrales, L., et al. (2017). Pluripotent nontumorigenic adipose tissue-derived muse cells have immunomodulatory capacity mediated by transforming growth factor- $\beta 1$. Stem Cells Transl. Med. 6, 161-173. doi: 10.5966/sctm.2016-0014

Go, V., Bowley, B. G. E., Pessina, M. A., Zhang, Z. G., Chopp, M., Finklestein, S. P., et al. (2020). Extracellular vesicles from mesenchymal stem cells reduce microglial-mediated neuroinflammation after cortical injury in aged Rhesus monkeys. Geroscience 42, 1-17. doi: 10.1007/s11357-019-00115-w

Gopalakrishnan, A., Shankarappa, S. A., and Rajanikant, G. K. (2019). Hydrogel Scaffolds: towards restitution of ischemic stroke-injured brain. Transl. Stroke Res. 10, 1-18. doi: 10.1007/s12975-018-0655-6

Grade, S., Weng, Y. C., Snapyan, M., Kriz, J., Malva, J. O., and Saghatelyan, A. (2013). Brain-derived neurotrophic factor promotes vasculature-associated migration of neuronal precursors toward the ischemic striatum. PLoS One 8:e55039. doi: 10.1371/journal.pone.0055039

Green, C., Minassian, A., Vogel, S., Diedenhofen, M., Beyrau, A., Wiedermann, D., et al. (2018). Sensorimotor functional and structural networks after intracerebral stem cell grafts in the ischemic mouse brain. J. Neurosci. 38, 1648-1661. doi: 10.1523/JNEUROSCI.2715-17.2018
Gronthos, S., Brahim, J., Li, W., Fisher, L. W., Cherman, N., Boyde, A., et al. (2002). Stem cell properties of human dental pulp stem cells. J. Dent. Res. 81, 531-535. doi: 10.1177/154405910208100806

Gronthos, S., Mankani, M., Brahim, J., Robey, P. G., and Shi, S. (2000). Postnatal human dental pulp stem cells (DPSCs) in vitro and in vivo. Proc. Natl. Acad. Sci. U.S.A. 97, 13625-13630. doi: 10.1073/pnas.240309797

Guo, D., Murdoch, C. E., Liu, T., Qu, J., Jiao, S., Wang, Y., et al. (2018). Therapeutic angiogenesis of Chinese herbal medicines in ischemic heart disease: a review. Front. Pharmacol. 9:428. doi: 10.3389/fphar.2018.00428

Gutiérrez-Fernández, M., Rodríguez-Frutos, B., Ramos-Cejudo, J., Teresa VallejoCremades, M., Fuentes, B., Cerdán, S., et al. (2013). Effects of intravenous administration of allogenic bone marrow- and adipose tissue-derived mesenchymal stem cells on functional recovery and brain repair markers in experimental ischemic stroke. Stem Cell Res. Ther. 4:11. doi: 10.1186/scrt159

Guzman, R., De Los Angeles, A., Cheshier, S., Choi, R., Hoang, S., Liauw, J., et al. (2008). Intracarotid injection of fluorescence activated cell-sorted CD49dpositive neural stem cells improves targeted cell delivery and behavior after stroke in a mouse stroke model. Stroke 39, 1300-1306. doi: 10.1161/strokeaha. 107.500470

Hatakeyama, M., Ninomiya, I., and Kanazawa, M. (2020a). Angiogenesis and neuronal remodeling after ischemic stroke. Neural Regen. Res. 15, 16-19. doi: 10.4103/1673-5374.264442

Hatakeyama, M., Ninomiya, I., Otsu, Y., Omae, K., Kimura, Y., Onodera, O., et al. (2020b). Cell therapies under clinical trials and polarized cell therapies in preclinical studies to treat ischemic stroke and neurological diseases: a literature review. Int. J. Mol. Sci. 21:6194. doi: 10.3390/ijms21176194

Helmstaedter, M. (2013). Cellular-resolution connectomics: challenges of dense neural circuit reconstruction. Nat. Methods 10, 501-507. doi: 10.1038/nmeth. 2476

Heneidi, S., Simerman, A., Keller, E., Singh, P., Li, X., Dumesic, D., et al. (2013). Awakened by cellular stress: isolation and characterization of a novel population of pluripotent stem cells derived from human adipose tissue. PLoS One 8:e64752. doi: 10.1371/journal.pone.0064752

Hennemann, B., Ickenstein, G., Sauerbruch, S., Luecke, K., Haas, S., Horn, M., et al. (2008). Mobilization of CD34+ hematopoietic cells, colony-forming cells and long-term culture-initiating cells into the peripheral blood of patients with an acute cerebral ischemic insult. Cytotherapy 10, 303-311. doi: 10.1080/ 14653240801949994

Herz, J., Sabellek, P., Lane, T., Gunzer, M., Hermann, D., and Doeppner, T. (2015). Role of neutrophils in exacerbation of brain injury after focal cerebral ischemia in hyperlipidemic mice. Stroke 46, 2916-2925. doi: 10.1161/strokeaha. 115.010620

Hess, D. C., Wechsler, L. R., Clark, W. M., Savitz, S. I., Ford, G. A., Chiu, D., et al. (2017). Safety and efficacy of multipotent adult progenitor cells in acute ischaemic stroke (MASTERS): a randomised, double-blind, placebo-controlled, phase 2 trial. Lancet Neurol. 16, 360-368. doi: 10.1016/s1474-4422(17)30046-7

Hira, K., Ueno, Y., Tanaka, R., Miyamoto, N., Yamashiro, K., Inaba, T., et al. (2018). Astrocyte-derived exosomes treated with a semaphorin 3A inhibitor enhance stroke recovery via prostaglandin d synthase. Stroke 49, 2483-2494. doi: 10.1161/strokeaha.118.021272

Honmou, O., Houkin, K., Matsunaga, T., Niitsu, Y., Ishiai, S., Onodera, R., et al. (2011). Intravenous administration of auto serum-expanded autologous mesenchymal stem cells in stroke. Brain 134(Pt 6), 1790-1807. doi: 10.1093/ brain/awr063

Hori, E., Hayakawa, Y., Hayashi, T., Hori, S., Okamoto, S., Shibata, T., et al. (2016). Mobilization of pluripotent multilineage-differentiating stress-enduring cells in ischemic stroke. J Stroke Cerebrovasc. Dis. 25, 1473-1481. doi: 10.1016/j. jstrokecerebrovasdis.2015.12.033

Hu, X., Li, P., Guo, Y., Wang, H., Leak, R., Chen, S., et al. (2012). Microglia/macrophage polarization dynamics reveal novel mechanism of injury expansion after focal cerebral ischemia. Stroke 43, 3063-3070. doi: 10.1161/ strokeaha.112.659656

Huang, J., Choudhri, T. F., Winfree, C. J., McTaggart, R. A., Kiss, S., Mocco, J., et al. (2000). Postischemic cerebrovascular E-selectin expression mediates tissue injury in murine stroke. Stroke 31, 3047-3053.

Huang, L., Wong, S., Snyder, E., Hamblin, M., and Lee, J. (2014). Human neural stem cells rapidly ameliorate symptomatic inflammation in early-stage 
ischemic-reperfusion cerebral injury. Stem Cell Res. Ther. 5:129. doi: 10.1186/ scrt519

Huang, W., Mo, X., Qin, C., Zheng, J., Liang, Z., and Zhang, C. (2013). Transplantation of differentiated bone marrow stromal cells promotes motor functional recovery in rats with stroke. Neurol. Res. 35, 320-328. doi: 10.1179/ $1743132812 y .0000000151$

Huang, W., Wang, C., Xie, L., Wang, X., Zhang, L., Chen, C., et al. (2019). Traditional two-dimensional mesenchymal stem cells (MSCs) are better than spheroid MSCs on promoting retinal ganglion cells survival and axon regeneration. Exp. Eye Res. 185:107699. doi: 10.1016/j.exer.2019.107699

Huang, Y., Wang, J., Cai, J., Qiu, Y., Zheng, H., Lai, X., et al. (2018). Targeted homing of CCR2-overexpressing mesenchymal stromal cells to ischemic brain enhances post-stroke recovery partially through PRDX4-mediated blood-brain barrier preservation. Theranostics 8, 5929-5944. doi: 10.7150/thno.28029

Icli, B., Wu, W., Ozdemir, D., Li, H., Haemmig, S., Liu, X., et al. (2019). MicroRNA$135 \mathrm{a}-3 \mathrm{p}$ regulates angiogenesis and tissue repair by targeting $\mathrm{p} 38$ signaling in endothelial cells. FASEB J. 33, 5599-5614. doi: 10.1096/fj.201802063RR

Ikegame, Y., Yamashita, K., Hayashi, S., Mizuno, H., Tawada, M., You, F., et al. (2011). Comparison of mesenchymal stem cells from adipose tissue and bone marrow for ischemic stroke therapy. Cytotherapy 13, 675-685. doi: 10.3109/ 14653249.2010.549122

Ilic, D., Devito, L., Miere, C., and Codognotto, S. (2015). Human embryonic and induced pluripotent stem cells in clinical trials. Br. Med. Bull. 116, 19-27. doi: $10.1093 / \mathrm{bmb} / \mathrm{ldv} 045$

Imai, F., Suzuki, H., Oda, J., Ninomiya, T., Ono, K., Sano, H., et al. (2007). Neuroprotective effect of exogenous microglia in global brain ischemia. J. Cereb. Blood Flow Metab. 27, 488-500. doi: 10.1038/sj.jcbfm.9600362

Jayaraj, R., Azimullah, S., Beiram, R., Jalal, F., and Rosenberg, G. (2019). Neuroinflammation: friend and foe for ischemic stroke. J. Neuroinflammation 16:142. doi: 10.1186/s12974-019-1516-2

Jeong, H., Yim, H. W., Cho, Y. S., Kim, Y. I., Jeong, S. N., Kim, H. B., et al. (2014). Efficacy and safety of stem cell therapies for patients with stroke: a systematic review and single arm meta-analysis. Int. J. Stem Cells 7, 63-69. doi: 10.15283/ijsc.2014.7.2.63

Jiang, C., Wang, J., Yu, L., Ou, C., Liu, X., Zhao, X., et al. (2013). Comparison of the therapeutic effects of bone marrow mononuclear cells and microglia for permanent cerebral ischemia. Behav. Brain Res. 250, 222-229. doi: 10.1016/j. bbr.2013.05.011

Jiang, X., Andjelkovic, A. V., Zhu, L., Yang, T., Bennett, M. V. L., Chen, J., et al. (2018). Blood-brain barrier dysfunction and recovery after ischemic stroke. Prog. Neurobiol. 163-164, 144-171. doi: 10.1016/j.pneurobio.2017.10.001

Jin, K., Mao, X. O., and Greenberg, D. A. (2006). Vascular endothelial growth factor stimulates neurite outgrowth from cerebral cortical neurons via Rho kinase signaling. J. Neurobiol. 66, 236-242. doi: 10.1002/neu.20215

Kalladka, D., Sinden, J., McLean, J., Moreton, F. C., Huang, X., and Muir, K. W. (2019). Increased deep grey matter functional connectivity of poststroke hNSC implanted ipsilesional putamen. J. Neurol. Neurosurg. Psychiatry 90, 959-960. doi: 10.1136/jnnp-2018-319022

Kalladka, D., Sinden, J., Pollock, K., Haig, C., McLean, J., Smith, W., et al. (2016). Human neural stem cells in patients with chronic ischaemic stroke (PISCES): a phase 1, first-in-man study. Lancet 388, 787-796. doi: 10.1016/s0140-6736(16) 30513-x

Kanazawa, M., Miura, M., Toriyabe, M., Koyama, M., Hatakeyama, M., Ishikawa, M., et al. (2017a). Microglia preconditioned by oxygen-glucose deprivation promote functional recovery in ischemic rats. Sci. Rep. 7:42582. doi: 10.1038/ srep 42582

Kanazawa, M., Ninomiya, I., Hatakeyama, M., Takahashi, T., and Shimohata, T. (2017b). Microglia and monocytes/macrophages polarization reveal novel therapeutic mechanism against stroke. Int. J. Mol. Sci. 18:2135. doi: 10.3390/ ijms 18102135

Kanazawa, M., Takahashi, T., Ishikawa, M., Onodera, O., Shimohata, T., Del Zoppo, G. J., et al. (2019). Angiogenesis in the ischemic core: a potential treatment target? J. Cereb. Blood Flow Metab. 39, 753-769. doi: 10.1177/ 0271678x19834158

Kang, L., Yu, H., Yang, X., Zhu, Y., Bai, X., Wang, R., et al. (2020). Neutrophil extracellular traps released by neutrophils impair revascularization and vascular remodeling after stroke. Nat. Commun. 11:2488. doi: 10.1038/s41467-02016191-y
Katagiri, H., Kushida, Y., Nojima, M., Kuroda, Y., Wakao, S., Ishida, K., et al. (2016). A distinct subpopulation of bone marrow mesenchymal stem cells, muse cells, directly commit to the replacement of liver components. Am. J. Transplant. 16, 468-483. doi: 10.1111/ajt.13537

Kawabori, M., Kuroda, S., Ito, M., Shichinohe, H., Houkin, K., Kuge, Y., et al. (2013). Timing and cell dose determine therapeutic effects of bone marrow stromal cell transplantation in rat model of cerebral infarct. Neuropathology 33 , 140-148. doi: 10.1111/j.1440-1789.2012.01335.x

Kawabori, M., Kuroda, S., Sugiyama, T., Ito, M., Shichinohe, H., Houkin, K., et al. (2012). Intracerebral, but not intravenous, transplantation of bone marrow stromal cells enhances functional recovery in rat cerebral infarct: an optical imaging study. Neuropathology 32, 217-226. doi: 10.1111/j.1440-1789.2011. 01260.x

Kawabori, M., Shichinohe, H., Kuroda, S., and Houkin, K. (2020a). Clinical trials of stem cell therapy for cerebral ischemic stroke. Int. J. Mol. Sci. 21:7380. doi: $10.3390 /$ ijms 21197380

Kawabori, M., Tanimori, A., Kitta, S., Shichinohe, H., and Houkin, K. (2020b). Evaluation of novel stereotactic cannula for stem cell transplantation against central nervous system disease. Stem Cells Int. 2020:4085617. doi: 10.1155/2020/ 4085617

Kelly, S., Bliss, T. M., Shah, A. K., Sun, G. H., Ma, M., Foo, W. C., et al. (2004). Transplanted human fetal neural stem cells survive, migrate, and differentiate in ischemic rat cerebral cortex. Proc. Natl. Acad. Sci. U.S.A. 101, 11839-11844. doi: 10.1073/pnas.0404474101

Kichenbrand, C., Velot, E., Menu, P., and Moby, V. (2019). Dental pulp stem cellderived conditioned medium: an attractive alternative for regenerative therapy. Tissue Eng. Part B Rev. 25, 78-88. doi: 10.1089/ten.TEB.2018.0168

Kikuchi-Taura, A., Okinaka, Y., Takeuchi, Y., Ogawa, Y., Maeda, M., Kataoka, Y., et al. (2020). Bone marrow mononuclear cells activate angiogenesis via gap junction-mediated cell-cell interaction. Stroke 51, 1279-1289. doi: 10.1161/ strokeaha.119.028072

Kim, J., and Hematti, P. (2009). Mesenchymal stem cell-educated macrophages: a novel type of alternatively activated macrophages. Exp. Hematol. 37, 1445-1453. doi: 10.1016/j.exphem.2009.09.004

Kim, S. J., Moon, G. J., Chang, W. H., Kim, Y. H., and Bang, O. Y. (2013). Intravenous transplantation of mesenchymal stem cells preconditioned with early phase stroke serum: current evidence and study protocol for a randomized trial. Trials 14:317. doi: 10.1186/1745-6215-14-317

Kondziolka, D., Steinberg, G. K., Wechsler, L., Meltzer, C. C., Elder, E., Gebel, J., et al. (2005). Neurotransplantation for patients with subcortical motor stroke: a phase 2 randomized trial. J. Neurosurg. 103, 38-45. doi: 10.3171/jns.2005.103.1. 0038

Kuroda, Y., Kitada, M., Wakao, S., Nishikawa, K., Tanimura, Y., Makinoshima, H., et al. (2010). Unique multipotent cells in adult human mesenchymal cell populations. Proc. Natl. Acad. Sci. U.S.A. 107, 8639-8643. doi: 10.1073/pnas. 0911647107

Kurozumi, K., Nakamura, K., Tamiya, T., Kawano, Y., Ishii, K., Kobune, M., et al. (2005). Mesenchymal stem cells that produce neurotrophic factors reduce ischemic damage in the rat middle cerebral artery occlusion model. Mol. Ther. 11, 96-104. doi: 10.1016/j.ymthe.2004.09.020

Lai, T., Zhang, S., and Wang, Y. (2014). Excitotoxicity and stroke: identifying novel targets for neuroprotection. Prog. Neurobiol. 115, 157-188. doi: 10.1016/ j.pneurobio.2013.11.006

Laskowitz, D. T., Bennett, E. R., Durham, R. J., Volpi, J. J., Wiese, J. R., Frankel, M., et al. (2018). Allogeneic umbilical cord blood infusion for adults with ischemic stroke: clinical outcomes from a phase I safety study. Stem Cells Transl. Med. 7, 521-529. doi: 10.1002/sctm.18-0008

Leal, G., Bramham, C. R., and Duarte, C. B. (2017). BDNF and hippocampal synaptic plasticity. Vitam. Horm. 104, 153-195. doi: 10.1016/bs.vh.2016.10.004

Lee, S., Kim, O. J., Lee, K. O., Jung, H., Oh, S. H., and Kim, N. K. (2020). Enhancing the therapeutic potential of CCL2-overexpressing mesenchymal stem cells in acute stroke. Int. J. Mol. Sci. 21:7795. doi: 10.3390/ijms2120 7795

Lee, S. T., Chu, K., Jung, K. H., Kim, S. J., Kim, D. H., Kang, K. M., et al. (2008). Anti-inflammatory mechanism of intravascular neural stem cell transplantation in haemorrhagic stroke. Brain 131(Pt 3), 616-629. doi: 10.1093/brain/awm306

Lee, W., Wong, H., Chai, Y., Shi, C., Amino, N., Kikuchi, S., et al. (2012). Lipid peroxidation dysregulation in ischemic stroke: plasma 4 -HNE as a potential 
biomarker? Biochem. Biophys. Res. Commun. 425, 842-847. doi: 10.1016/j.bbrc. 2012.08.002

Levy, M. L., Crawford, J. R., Dib, N., Verkh, L., Tankovich, N., and Cramer, S. C. (2019). Phase I/II study of safety and preliminary efficacy of intravenous allogeneic mesenchymal stem cells in chronic stroke. Stroke 50, 2835-2841. doi: $10.1161 /$ strokeaha. 119.026318

Li, J., Tao, T., Xu, J., Liu, Z., Zou, Z., and Jin, M. (2020a). HIF-1 $\alpha$ attenuates neuronal apoptosis by upregulating EPO expression following cerebral ischemia-reperfusion injury in a rat MCAO model. Int. J. Mol. Med. 45, 1027-1036. doi: 10.3892/ijmm.2020.4480

Li, J., Zhang, Q., Wang, W., Lin, F., Wang, S., and Zhao, J. (2020b). Mesenchymal stem cell therapy for ischemic stroke: a look into treatment mechanism and therapeutic potential. J. Neurol. doi: 10.1007/s00415-020-10138-5 [Epub ahead of print].

Li, P., Hu, X., Gan, Y., Gao, Y., Liang, W., and Chen, J. (2011). Mechanistic insight into DNA damage and repair in ischemic stroke: exploiting the base excision repair pathway as a model of neuroprotection. Antioxid. Redox Signal. 14, 1905-1918. doi: 10.1089/ars.2010.3451

Li, X., and Carmeliet, P. (2018). Targeting angiogenic metabolism in disease. Science 359, 1335-1336. doi: 10.1126/science.aar5557

Liddelow, S., and Barres, B. (2017). Reactive astrocytes: production, function, and therapeutic potential. Immunity 46, 957-967. doi: 10.1016/j.immuni.2017. 06.006

Lindsay, M., Norrving, B., Sacco, R., Brainin, M., Hacke, W., Martins, S., et al. (2019). World Stroke Organization (WSO): global stroke fact sheet 2019. Int. J. Stroke 14, 806-817. doi: 10.1177/1747493019881353

Lippmann, E. S., Azarin, S. M., Palecek, S. P., and Shusta, E. V. (2020). Commentary on human pluripotent stem cell-based blood-brain barrier models. Fluids Barriers CNS 17:64. doi: 10.1186/s12987-020-00222-3

Liu, B., Liao, M., Mielke, J., Ning, K., Chen, Y., Li, L., et al. (2006). Ischemic insults direct glutamate receptor subunit 2-lacking AMPA receptors to synaptic sites. J. Neurosci. 26, 5309-5319. doi: 10.1523/jneurosci.0567-06.2006

Luo, W., Liu, T., Li, S., Wen, H., Zhou, F., Zafonte, R., et al. (2019). The serum BDNF level offers minimum predictive value for motor function recovery after stroke. Transl. Stroke Res. 10, 342-351. doi: 10.1007/s12975-018-0648-5

Martens, W., Bronckaers, A., Politis, C., Jacobs, R., and Lambrichts, I. (2013). Dental stem cells and their promising role in neural regeneration: an update. Clin. Oral Investig. 17, 1969-1983. doi: 10.1007/s00784-013-1030-3

Mayadas, T., Cullere, X., and Lowell, C. (2014). The multifaceted functions of neutrophils. Annu. Rev. Pathol. 9, 181-218. doi: 10.1146/annurev-pathol020712-164023

Mine, Y., Tatarishvili, J., Oki, K., Monni, E., Kokaia, Z., and Lindvall, O. (2013). Grafted human neural stem cells enhance several steps of endogenous neurogenesis and improve behavioral recovery after middle cerebral artery occlusion in rats. Neurobiol. Dis. 52, 191-203. doi: 10.1016/j.nbd.2012.12.006

Misra, V., Ritchie, M. M., Stone, L. L., Low, W. C., and Janardhan, V. (2012). Stem cell therapy in ischemic stroke: role of IV and intra-arterial therapy. Neurology 79(13 Suppl. 1), S207-S212. doi: 10.1212/WNL.0b013e31826959d2

Modo, M., Mellodew, K., Cash, D., Fraser, S., Meade, T., Price, J., et al. (2004). Mapping transplanted stem cell migration after a stroke: a serial, in vivo magnetic resonance imaging study. Neuroimage 21, 311-317. doi: 10.1016/j. neuroimage.2003.08.030

Moghe, A., Ghare, S., Lamoreau, B., Mohammad, M., Barve, S., McClain, C., et al. (2015). Molecular mechanisms of acrolein toxicity: relevance to human disease. Toxicol Sci 143, 242-255. doi: 10.1093/toxsci/kfu233

Mohamed, I., Ishrat, T., Fagan, S., and El-Remessy, A. (2015). Role of inflammasome activation in the pathophysiology of vascular diseases of the neurovascular unit. Antioxid Redox Signal 22, 1188-1206. doi: 10.1089/ars.2014. 6126

Moll, N. M., and Ransohoff, R. M. (2010). CXCL12 and CXCR4 in bone marrow physiology. Expert. Rev. Hematol. 3, 315-322. doi: 10.1586/ehm.10.16

Moon, G., Sung, J., Kim, D., Kim, E., Cho, Y., Son, J., et al. (2019). Application of mesenchymal stem cell-derived extracellular vesicles for stroke: biodistribution and microRNA study. Transl. Stroke Res. 10, 509-521. doi: 10.1007/s12975-0180668-1

Moshayedi, P., Nih, L. R., Llorente, I. L., Berg, A. R., Cinkornpumin, J., Lowry, W. E., et al. (2016). Systematic optimization of an engineered hydrogel allows for selective control of human neural stem cell survival and differentiation after transplantation in the stroke brain. Biomaterials 105, 145-155. doi: 10.1016/j. biomaterials.2016.07.028

Moubarik, C., Guillet, B., Youssef, B., Codaccioni, J., Piercecchi, M., Sabatier, F., et al. (2011). Transplanted late outgrowth endothelial progenitor cells as cell therapy product for stroke. Stem Cell Rev. Rep. 7, 208-220. doi: 10.1007/s12015010-9157-y

Mozaffarian, D., Benjamin, E., Go, A., Arnett, D., Blaha, M., Cushman, M., et al. (2016). Executive summary: heart disease and stroke statistics-2016 update: a report from the American heart association. Circulation 133, 447-454. doi: 10.1161/cir.0000000000000366

Muir, K. W., Bulters, D., Willmot, M., Sprigg, N., Dixit, A., Ward, N., et al. (2020). Intracerebral implantation of human neural stem cells and motor recovery after stroke: multicentre prospective single-arm study (PISCES-2). J. Neurol. Neurosurg. Psychiatry 91, 396-401. doi: 10.1136/jnnp-2019-322515

Muralikrishna Adibhatla, R., and Hatcher, J. (2006). Phospholipase A2, reactive oxygen species, and lipid peroxidation in cerebral ischemia. Free Rad. Biol. Med. 40, 376-387. doi: 10.1016/j.freeradbiomed.2005.08.044

Murphy, C. M., Haugh, M. G., and O'Brien, F. J. (2010). The effect of mean pore size on cell attachment, proliferation and migration in collagen-glycosaminoglycan scaffolds for bone tissue engineering. Biomaterials 31, 461-466. doi: 10.1016/j. biomaterials.2009.09.063

Murry, C. E., and Keller, G. (2008). Differentiation of embryonic stem cells to clinically relevant populations: lessons from embryonic development. Cell 132, 661-680. doi: 10.1016/j.cell.2008.02.008

Nagpal, A., Kremer, K. L., Hamilton-Bruce, M. A., Kaidonis, X., Milton, A. G., Levi, C., et al. (2016). TOOTH (The open study of dental pulp stem cell therapy in humans): study protocol for evaluating safety and feasibility of autologous human adult dental pulp stem cell therapy in patients with chronic disability after stroke. Int. J. Stroke 11, 575-585. doi: 10.1177/174749301664 1111

Nakayama, D., Matsuyama, T., Ishibashi-Ueda, H., Nakagomi, T., Kasahara, Y., Hirose, H., et al. (2010). Injury-induced neural stem/progenitor cells in poststroke human cerebral cortex. Eur. J. Neurosci. 31, 90-98. doi: 10.1111/j.14609568.2009.07043.x

Nathan, C. (2006). Neutrophils and immunity: challenges and opportunities. Nat. Rev. Immunol. 6, 173-182. doi: 10.1038/nri1785

Neuhuber, B., Timothy Himes, B., Shumsky, J. S., Gallo, G., and Fischer, I. (2005). Axon growth and recovery of function supported by human bone marrow stromal cells in the injured spinal cord exhibit donor variations. Brain Res. 1035, 73-85. doi: 10.1016/j.brainres.2004.11.055

Neumann, S., Shields, N., Balle, T., Chebib, M., and Clarkson, A. (2015). Innate immunity and inflammation post-stroke: an $\alpha 7$-Nicotinic agonist perspective. Int. J. Mol. Sci. 16, 29029-29046. doi: 10.3390/ijms161226141

Niizuma, K., Borlongan, C., and Tominaga, T. (2018). Application of muse cell therapy to stroke. Adv. Exp. Med. Biol. 1103, 167-186. doi: 10.1007/978-4-43156847-6_9

Niki, E. (2009). Lipid peroxidation: physiological levels and dual biological effects. Free Rad. Biol. Med. 47, 469-484. doi: 10.1016/j.freeradbiomed.2009.05.032

Nito, C., Sowa, K., Nakajima, M., Sakamoto, Y., Suda, S., Nishiyama, Y., et al. (2018). Transplantation of human dental pulp stem cells ameliorates brain damage following acute cerebral ischemia. Biomed. Pharmacother. 108, 10051014. doi: 10.1016/j.biopha.2018.09.084

Nosrat, I. V., Smith, C. A., Mullally, P., Olson, L., and Nosrat, C. A. (2004). Dental pulp cells provide neurotrophic support for dopaminergic neurons and differentiate into neurons in vitro; implications for tissue engineering and repair in the nervous system. Eur. J. Neurosci. 19, 2388-2398. doi: 10.1111/j.0953816X.2004.03314.x

Obernier, K., and Alvarez-Buylla, A. (2019). Neural stem cells: origin, heterogeneity and regulation in the adult mammalian brain. Development 146:dev156059. doi: 10.1242/dev.156059

Obrenovitch, T., Urenjak, J., Richards, D., Ueda, Y., Curzon, G., and Symon, L. (1993). Extracellular neuroactive amino acids in the rat striatum during ischaemia: comparison between penumbral conditions and ischaemia with sustained anoxic depolarisation. J. Neurochem. 61, 178-186. doi: 10.1111/j. 1471-4159.1993.tb03553.x

Ojeh, N., Pastar, I., Tomic-Canic, M., and Stojadinovic, O. (2015). Stem cells in skin regeneration, wound healing, and their clinical applications. Int. J. Mol. Sci. 16, 25476-25501. doi: 10.3390/ijms161025476 
Olney, J. (1969). Brain lesions, obesity, and other disturbances in mice treated with monosodium glutamate. Science (New York, N.Y.) 164, 719-721. doi: 10.1126/ science.164.3880.719

Ottoboni, L., von Wunster, B., and Martino, G. (2020). Therapeutic plasticity of neural stem cells. Front. Neurol. 11:148. doi: 10.3389/fneur.2020.00148

Özdemir, A. T., Özgül Özdemir, R. B., Kırmaz, C., Sarıboyac $\iota$, A. E., Ünal Halbutoðllarl, Z. S., Özel, C., et al. (2016). The paracrine immunomodulatory interactions between the human dental pulp derived mesenchymal stem cells and CD4 T cell subsets. Cell Immunol. 310, 108-115. doi: 10.1016/j.cellimm. 2016.08.008

Palma-Tortosa, S., Hurtado, O., Pradillo, J. M., Ferreras-Martín, R., GarcíaYébenes, I., García-Culebras, A., et al. (2019). Toll-like receptor 4 regulates subventricular zone proliferation and neuroblast migration after experimental stroke. Brain Behav. Immun. 80, 573-582. doi: 10.1016/j.bbi.2019.05.002

Pan, Q., Zheng, J., Du, D., Liao, X., Ma, C., Yang, Y., et al. (2018). MicroRNA-126 priming enhances functions of endothelial progenitor cells under physiological and hypoxic conditions and their therapeutic efficacy in cerebral ischemic damage. Stem Cells Int. 2018:2912347. doi: 10.1155/2018/2912347

Pendharkar, A. V., Chua, J. Y., Andres, R. H., Wang, N., Gaeta, X., Wang, H., et al. (2010). Biodistribution of neural stem cells after intravascular therapy for hypoxic-ischemia. Stroke 41, 2064-2070. doi: 10.1161/strokeaha.109.575993

Peng, P., Zhong, X., Tu, W., Soundarapandian, M., Molner, P., Zhu, D., et al. (2006). ADAR2-dependent RNA editing of AMPA receptor subunit GluR2 determines vulnerability of neurons in forebrain ischemia. Neuron 49, 719-733. doi: 10.1016/j.neuron.2006.01.025

Pierdomenico, L., Bonsi, L., Calvitti, M., Rondelli, D., Arpinati, M., Chirumbolo, G., et al. (2005). Multipotent mesenchymal stem cells with immunosuppressive activity can be easily isolated from dental pulp. Transplantation 80, 836-842. doi: 10.1097/01.tp.0000173794.72151.88

Ping, S., Qiu, X., Kyle, M., Hughes, K., Longo, J., and Zhao, L. R. (2019). Stem cell factor and granulocyte colony-stimulating factor promote brain repair and improve cognitive function through VEGF-A in a mouse model of CADASIL. Neurobiol. Dis. 132:104561. doi: 10.1016/j.nbd.2019.104561

Ponnaiyan, D., and Jegadeesan, V. (2014). Comparison of phenotype and differentiation marker gene expression profiles in human dental pulp and bone marrow mesenchymal stem cells. Eur. J. Dent. 8, 307-313. doi: 10.4103/13057456.137631

Potz, B. A., Scrimgeour, L. A., Pavlov, V. I., Sodha, N. R., Abid, M. R., and Sellke, F. W. (2018). Extracellular vesicle injection improves myocardial function and increases angiogenesis in a swine model of chronic ischemia. J. Am. Heart Assoc. 7:8344. doi: 10.1161/jaha.117.008344

Prasad, K., Sharma, A., Garg, A., Mohanty, S., Bhatnagar, S., Johri, S., et al. (2014). Intravenous autologous bone marrow mononuclear stem cell therapy for ischemic stroke: a multicentric, randomized trial. Stroke 45, 3618-3624. doi: 10.1161/strokeaha.114.007028

Qiu, G., Zheng, G., Ge, M., Wang, J., Huang, R., Shu, Q., et al. (2018). Mesenchymal stem cell-derived extracellular vesicles affect disease outcomes via transfer of microRNAs. Stem Cell Res. Ther. 9:320. doi: 10.1186/s13287-018-1069-9

Rabenstein, M., Hucklenbroich, J., Willuweit, A., Ladwig, A., Fink, G. R., Schroeter, M., et al. (2015). Osteopontin mediates survival, proliferation and migration of neural stem cells through the chemokine receptor CXCR4. Stem Cell Res. Ther. 6:99. doi: 10.1186/s13287-015-0098-x

Raposo, G., and Stoorvogel, W. (2013). Extracellular vesicles: exosomes, microvesicles, and friends. J. Cell Biol. 200, 373-383. doi: 10.1083/jcb. 201211138

Ratajczak, M. Z., Ratajczak, J., and Kucia, M. (2019). Very small embryonic-like stem cells (VSELs). Circ. Res. 124, 208-210. doi: 10.1161/circresaha.118.314287

Rikhtegar, R., Yousefi, M., Dolati, S., Kasmaei, H., Charsouei, S., Nouri, M., et al. (2019). Stem cell-based cell therapy for neuroprotection in stroke: a review. J. Cell. Biochem. 120, 8849-8862. doi: 10.1002/jcb.28207

Rosenblum, S., Smith, T. N., Wang, N., Chua, J. Y., Westbroek, E., Wang, K., et al. (2015). BDNF pretreatment of human embryonic-derived neural stem cells improves cell survival and functional recovery after transplantation in hypoxic-ischemic stroke. Cell Transplant. 24, 2449-2461. doi: 10.3727/ $096368914 \times 679354$

Roth, J. M. (2011). Recombinant tissue plasminogen activator for the treatment of acute ischemic stroke. Proc. (Bayl. Univ. Med. Cent.) 24, 257-259. doi: 10.1080/ 08998280.2011 .11928729
Ruan, L., Wang, B., ZhuGe, Q., and Jin, K. (2015). Coupling of neurogenesis and angiogenesis after ischemic stroke. Brain Res. 1623, 166-173. doi: 10.1016/j. brainres.2015.02.042

Rundek, T., and Sacco, R. (2008). Risk factor management to prevent first stroke. Neurol. Clin. 26, 1007-1045,ix. doi: 10.1016/j.ncl.2008.09.001

Sakai, K., Yamamoto, A., Matsubara, K., Nakamura, S., Naruse, M., Yamagata, M., et al. (2012). Human dental pulp-derived stem cells promote locomotor recovery after complete transection of the rat spinal cord by multiple neuroregenerative mechanisms. J. Clin. Invest. 122, 80-90. doi: 10.1172/jci59251

Sato, Y., Bando, H., Di Piazza, M., Gowing, G., Herberts, C., Jackman, S., et al. (2019). Tumorigenicity assessment of cell therapy products: the need for global consensus and points to consider. Cytotherapy 21, 1095-1111. doi: 10.1016/j. jcyt.2019.10.001

Savitz, S. I., Chopp, M., Deans, R., Carmichael, T., Phinney, D., and Wechsler, L. (2011a). Stem cell therapy as an emerging paradigm for stroke (STEPS) II. Stroke 42, 825-829. doi: 10.1161/strokeaha.110.601914

Savitz, S. I., Dinsmore, J., Wu, J., Henderson, G. V., Stieg, P., and Caplan, L. R. (2005). Neurotransplantation of fetal porcine cells in patients with basal ganglia infarcts: a preliminary safety and feasibility study. Cerebrovasc. Dis. 20, 101-107. doi: $10.1159 / 000086518$

Savitz, S. I., Misra, V., Kasam, M., Juneja, H., Cox, C. S. Jr., Alderman, S., et al. (2011b). Intravenous autologous bone marrow mononuclear cells for ischemic stroke. Ann. Neurol. 70, 59-69. doi: 10.1002/ana.22458

Schäbitz, W., Sommer, C., Zoder, W., Kiessling, M., Schwaninger, M., and Schwab, S. (2000). Intravenous brain-derived neurotrophic factor reduces infarct size and counterregulates Bax and Bcl-2 expression after temporary focal cerebral ischemia. Stroke 31, 2212-2217. doi: 10.1161/01.str.31.9.2212

Sheikh, A. M., Yano, S., Mitaki, S., Haque, M. A., Yamaguchi, S., and Nagai, A. (2019). A mesenchymal stem cell line (B10) increases angiogenesis in a rat MCAO model. Exp. Neurol. 311, 182-193. doi: 10.1016/j.expneurol.2018. 10.001

Shen, Q., Goderie, S. K., Jin, L., Karanth, N., Sun, Y., Abramova, N., et al. (2004). Endothelial cells stimulate self-renewal and expand neurogenesis of neural stem cells. Science 304, 1338-1340. doi: 10.1126/science.1095505

Shetty, A. K., and Hattiangady, B. (2016). Grafted subventricular zone neural stem cells display robust engraftment and similar differentiation properties and form new neurogenic niches in the young and aged hippocampus. Stem Cells Transl. Med. 5, 1204-1215. doi: 10.5966/sctm.2015-0270

Shi, K., Tian, D., Li, Z., Ducruet, A., Lawton, M., and Shi, F. (2019). Global brain inflammation in stroke. Lancet Neurol. 18, 1058-1066. doi: 10.1016/s14744422(19)30078-x

Shichinohe, H., Ishihara, T., Takahashi, K., Tanaka, Y., Miyamoto, M., Yamauchi, T., et al. (2015). Bone marrow stromal cells rescue ischemic brain by trophic effects and phenotypic change toward neural cells. Neurorehabil. Neural Repair 29, 80-89. doi: 10.1177/1545968314525856

Shichinohe, H., Kawabori, M., Iijima, H., Teramoto, T., Abumiya, T., Nakayama, N., et al. (2017). Research on advanced intervention using novel bone marrOW stem cell (RAINBOW): a study protocol for a phase I, open-label, uncontrolled, dose-response trial of autologous bone marrow stromal cell transplantation in patients with acute ischemic stroke. BMC Neurol. 17:179. doi: 10.1186/s12883017-0955-6

Song, M., Jue, S. S., Cho, Y. A., and Kim, E. C. (2015). Comparison of the effects of human dental pulp stem cells and human bone marrow-derived mesenchymal stem cells on ischemic human astrocytes in vitro. J. Neurosci. Res. 93, 973-983. doi: 10.1002/jnr.23569

Song, M., Lee, J. H., Bae, J., Bu, Y., and Kim, E. C. (2017). Human dental pulp stem cells are more effective than human bone marrow-derived mesenchymal stem cells in cerebral ischemic injury. Cell Transplant. 26, 1001-1016. doi: $10.3727 / 096368916$ X694391

Sotomayor-Sobrino, M. A., Ochoa-Aguilar, A., Méndez-Cuesta, L. A., and GómezAcevedo, C. (2019). Neuroimmunological interactions in stroke. Neurologia 34, 326-335. doi: 10.1016/j.nrl.2016.08.003

Southan, G., and Szabó, C. (2003). Poly(ADP-ribose) polymerase inhibitors. Curr. Med. Chem. 10, 321-340. doi: 10.2174/0929867033368376

Sovalat, H., Scrofani, M., Eidenschenk, A., Pasquet, S., Rimelen, V., and Hénon, P. (2011). Identification and isolation from either adult human bone marrow or G-CSF-mobilized peripheral blood of CD34(+)/CD133(+)/CXCR4(+)/ Lin(-)CD45(-) cells, featuring morphological, molecular, and phenotypic 
characteristics of very small embryonic-like (VSEL) stem cells. Exp. Hematol. 39, 495-505. doi: 10.1016/j.exphem.2011.01.003

Spellicy, S. E., and Stice, S. L. (2020). Tissue and stem cell sourced extracellular vesicle communications with microglia. Stem Cell Rev. Rep. doi: 10.1007/ s12015-020-10011-y [Epub ahead of print].

Steinberg, G. K., Kondziolka, D., Wechsler, L. R., Lunsford, L. D., Coburn, M. L., Billigen, J. B., et al. (2016). Clinical outcomes of transplanted modified bone marrow-derived mesenchymal stem cells in stroke: a phase 1/2a study. Stroke 47, 1817-1824. doi: 10.1161/strokeaha.116.012995

Steinberg, G. K., Kondziolka, D., Wechsler, L. R., Lunsford, L. D., Kim, A. S., Johnson, J. N., et al. (2018). Two-year safety and clinical outcomes in chronic ischemic stroke patients after implantation of modified bone marrow-derived mesenchymal stem cells (SB623): a phase 1/2a study. J. Neurosurg. 131, 1-11. doi: 10.3171/2018.5.Jns 173147

Stonesifer, C., Corey, S., Ghanekar, S., Diamandis, Z., Acosta, S. A., and Borlongan, C. V. (2017). Stem cell therapy for abrogating stroke-induced neuroinflammation and relevant secondary cell death mechanisms. Prog. Neurobiol. 158, 94-131. doi: 10.1016/j.pneurobio.2017.07.004

Suda, S., Nito, C., Yokobori, S., Sakamoto, Y., Nakajima, M., Sowa, K., et al. (2020). Recent Advances in cell-based therapies for ischemic stroke. Int. J. Mol. Sci. 21:6718. doi: $10.3390 /$ ijms 21186718

Sullivan, R., Duncan, K., Dailey, T., Kaneko, Y., Tajiri, N., and Borlongan, C. V. (2015). A possible new focus for stroke treatment - migrating stem cells. Expert Opin. Biol. Ther. 15, 949-958. doi: 10.1517/14712598.2015.1043264

Taguchi, A., Sakai, C., Soma, T., Kasahara, Y., Stern, D. M., Kajimoto, K., et al. (2015). Intravenous autologous bone marrow mononuclear cell transplantation for stroke: phase1/2a clinical trial in a homogeneous group of stroke patients. Stem Cells Dev. 24, 2207-2218. doi: 10.1089/scd.2015.0160

Takahashi, K., Tanabe, K., Ohnuki, M., Narita, M., Ichisaka, T., Tomoda, K., et al. (2007). Induction of pluripotent stem cells from adult human fibroblasts by defined factors. Cell 131, 861-872. doi: 10.1016/j.cell.2007.11.019

Takahashi, K., and Yamanaka, S. J. C. (2006). Induction of pluripotent stem cells from mouse embryonic and adult fibroblast cultures by defined factors. Cell 126, 663-676. doi: 10.1016/j.cell.2006.07.024

Tan, C., Zhao, S., Higashikawa, K., Wang, Z., Kawabori, M., Abumiya, T., et al. (2018). [F]DPA-714 PET imaging shows immunomodulatory effect of intravenous administration of bone marrow stromal cells after transient focal ischemia. EJNMMI Res. 8:35. doi: 10.1186/s13550-018-0392-6

Terada, N., Hamazaki, T., Oka, M., Hoki, M., Mastalerz, D., Nakano, Y., et al. (2002). Bone marrow cells adopt the phenotype of other cells by spontaneous cell fusion. Nature 416, 542-545. doi: 10.1038/nature730

Terry, T., Chen, Z., Dixon, R., Vanderslice, P., Zoldhelyi, P., Willerson, J., et al. (2011). $\mathrm{CD}^{+} 4^{+} / \mathrm{M}$-cadherin ${ }^{+}$bone marrow progenitor cells promote arteriogenesis in ischemic hindlimbs of $\mathrm{ApoE}^{-} /^{-}$mice. PLoS One 6:e20673. doi: 10.1371/journal.pone.0020673

Thomalla, G., and Gerloff, C. (2019). Acute imaging for evidence-based treatment of ischemic stroke. Curr. Opin. Neurol. 32, 521-529. doi: 10.1097/wco. 0000000000000716

Tobin, M. K., Stephen, T. K. L., Lopez, K. L., Pergande, M. R., Bartholomew, A. M., Cologna, S. M., et al. (2020). Activated mesenchymal stem cells induce recovery following stroke via regulation of inflammation and oligodendrogenesis. J. Am. Heart Assoc. 9:e013583. doi: 10.1161/JAHA.119. 013583

Toyama, K., Honmou, O., Harada, K., Suzuki, J., Houkin, K., Hamada, H., et al. (2009). Therapeutic benefits of angiogenetic gene-modified human mesenchymal stem cells after cerebral ischemia. Exp. Neurol. 216, 47-55. doi: 10.1016/j.expneurol.2008.11.010

Toyoshima, A., Yasuhara, T., Kameda, M., Morimoto, J., Takeuchi, H., Wang, F., et al. (2015). Intra-arterial transplantation of allogeneic mesenchymal stem cells mounts neuroprotective effects in a transient ischemic stroke model in rats: analyses of therapeutic time window and its mechanisms. PLoS One 10:e0127302. doi: 10.1371/journal.pone.0127302

Trounson, A., and McDonald, C. (2015). Stem cell therapies in clinical trials: progress and challenges. Cell Stem Cell 17, 11-22. doi: 10.1016/j.stem.2015. 06.007

Tsai, P. T., Ohab, J. J., Kertesz, N., Groszer, M., Matter, C., Gao, J., et al. (2006). A critical role of erythropoietin receptor in neurogenesis and post-stroke recovery. J. Neurosci. 26, 1269-1274. doi: 10.1523/jneurosci.4480-05.2006
Tseng, K. Y., Anttila, J. E., Khodosevich, K., Tuominen, R. K., Lindahl, M., Domanskyi, A., et al. (2018). MANF promotes differentiation and migration of neural progenitor cells with potential neural regenerative effects in stroke. Mol. Ther. 26, 238-255. doi: 10.1016/j.ymthe.2017.09.019

Tziomalos, K., Athyros, V., Karagiannis, A., and Mikhailidis, D. (2009). Dyslipidemia as a risk factor for ischemic stroke. Curr. Top. Med. Chem. 9, 1291-1297. doi: 10.2174/156802609789869628

Uchida, H., Morita, T., Niizuma, K., Kushida, Y., Kuroda, Y., Wakao, S., et al. (2016). Transplantation of unique subpopulation of fibroblasts, muse cells, ameliorates experimental stroke possibly via robust neuronal differentiation. Stem Cells 34, 160-173. doi: 10.1002/stem.2206

Uchida, H., Niizuma, K., Kushida, Y., Wakao, S., Tominaga, T., Borlongan, C. V., et al. (2017). Human muse cells reconstruct neuronal circuitry in subacute lacunar stroke model. Stroke 48, 428-435. doi: 10.1161/strokeaha.116.014950

Uchida, N., Kushida, Y., Kitada, M., Wakao, S., Kumagai, N., Kuroda, Y., et al. (2017). Beneficial effects of systemically administered human muse cells in adriamycin nephropathy. J. Am. Soc. Nephrol. 28, 2946-2960. doi: 10.1681/asn. 2016070775

Uemura, M., Kasahara, Y., Nagatsuka, K., and Taguchi, A. (2012). Cell-based therapy to promote angiogenesis in the brain following ischemic damage. Curr. Vasc. Pharmacol. 10, 285-288. doi: 10.2174/157016112799959369

Urban, C., Ermert, D., Schmid, M., Abu-Abed, U., Goosmann, C., Nacken, W., et al. (2009). Neutrophil extracellular traps contain calprotectin, a cytosolic protein complex involved in host defense against Candida albicans. PLoS Pathog. 5:e1000639. doi: 10.1371/journal.ppat.1000639

Vahidy, F. S., Haque, M. E., Rahbar, M. H., Zhu, H., Rowan, P., Aisiku, I. P., et al. (2019). Intravenous bone marrow mononuclear cells for acute ischemic stroke: safety, feasibility, and effect size from a phase I clinical trial. Stem Cells 37, 1481-1491. doi: 10.1002/stem.3080

Valencia, J., Blanco, B., Yáñez, R., Vázquez, M., Herrero Sánchez, C., FernándezGarcía, M., et al. (2016). Comparative analysis of the immunomodulatory capacities of human bone marrow- and adipose tissue-derived mesenchymal stromal cells from the same donor. Cytotherapy 18, 1297-1311. doi: 10.1016/j. jcyt.2016.07.006

Vasconcelos-dos-Santos, A., Rosado-de-Castro, P. H., Lopes de Souza, S. A., da Costa, Silva, J., Ramos, A. B., et al. (2012). Intravenous and intra-arterial administration of bone marrow mononuclear cells after focal cerebral ischemia: Is there a difference in biodistribution and efficacy? Stem Cell Res. 9, 1-8. doi: 10.1016/j.scr.2012.02.002

Vitrac, A., and Cloëz-Tayarani, I. (2018). Induced pluripotent stem cells as a tool to study brain circuits in autism-related disorders. Stem Cell Res. Ther. 9:226. doi: 10.1186/s13287-018-0966-2

Vonderwalde, I., Azimi, A., Rolvink, G., Ahlfors, J., Shoichet, M., and Morshead, C. M. (2020). Transplantation of directly reprogrammed human neural precursor cells following stroke promotes synaptogenesis and functional recovery. Transl. Stroke Res. 11, 93-107. doi: 10.1007/s12975-019-0691-x

Wagenaar, N., de Theije, C. G. M., de Vries, L. S., Groenendaal, F., Benders, M., and Nijboer, C. H. A. (2018). Promoting neuroregeneration after perinatal arterial ischemic stroke: neurotrophic factors and mesenchymal stem cells. Pediatr. Res. 83, 372-384. doi: 10.1038/pr.2017.243

Wakabayashi, K., Nagai, A., Sheikh, A. M., Shiota, Y., Narantuya, D., Watanabe, T., et al. (2010). Transplantation of human mesenchymal stem cells promotes functional improvement and increased expression of neurotrophic factors in a rat focal cerebral ischemia model. J Neurosci Res 88, 1017-1025. doi: 10.1002/ jnr.22279

Wakao, S., Kitada, M., Kuroda, Y., Shigemoto, T., Matsuse, D., Akashi, H., et al. (2011). Multilineage-differentiating stress-enduring (Muse) cells are a primary source of induced pluripotent stem cells in human fibroblasts. Proc. Natl. Acad. Sci. U.S.Am. 108, 9875-9880. doi: 10.1073/pnas.1100816108

Walczak, P., Zhang, J., Gilad, A. A., Kedziorek, D. A., Ruiz-Cabello, J., Young, R. G., et al. (2008). Dual-modality monitoring of targeted intraarterial delivery of mesenchymal stem cells after transient ischemia. Stroke 39, 1569-1574. doi: 10.1161/strokeaha.107.502047

Wang, G., and Thayer, S. (1996). Sequestration of glutamate-induced Ca2+ loads by mitochondria in cultured rat hippocampal neurons. J. Neurophysiol. 76, 1611-1621. doi: 10.1152/jn.1996.76.3.1611

Wang, J., Liu, X., Lu, H., Jiang, C., Cui, X., Yu, L., et al. (2015). CXCR4(+)CD45(-) BMMNC subpopulation is superior to unfractionated BMMNCs for protection 
after ischemic stroke in mice. Brain Behav. Immun. 45, 98-108. doi: 10.1016/j. bbi.2014.12.015

Wang, J., Yu, L., Jiang, C., Chen, M., Ou, C., and Wang, J. (2013). Bone marrow mononuclear cells exert long-term neuroprotection in a rat model of ischemic stroke by promoting arteriogenesis and angiogenesis. Brain Behav. Immun. 34, 56-66. doi: 10.1016/j.bbi.2013.07.010

Wang, L., Ji, H., Li, M., Zhou, J., Bai, W., Zhong, Z., et al. (2013). Intrathecal administration of autologous CD34 positive cells in patients with past cerebral infarction: a safety study. ISRN Neurol. 2013, 128591. doi: 10.1155/2013/128591

Wang, L., Li, Y., Chen, X., Chen, J., Gautam, S. C., Xu, Y., et al. (2002). MCP1, MIP-1, IL-8 and ischemic cerebral tissue enhance human bone marrow stromal cell migration in interface culture. Hematology 7, 113-117. doi: 10.1080/ 10245330290028588

Wang, L. Q., Lin, Z. Z., Zhang, H. X., Shao, B., Xiao, L., Jiang, H. G., et al. (2014). Timing and dose regimens of marrow mesenchymal stem cell transplantation affect the outcomes and neuroinflammatory response after ischemic stroke. CNS Neurosci. Ther. 20, 317-326. doi: 10.1111/cns.12216

Wang, Q., Duan, F., Wang, M. X., Wang, X. D., Liu, P., and Ma, L. Z. (2016). Effect of stem cell-based therapy for ischemic stroke treatment: a meta-analysis. Clin. Neurol. Neurosurg. 146, 1-11. doi: 10.1016/j.clineuro.2016.04.011

Wardlaw, J. M., Murray, V., Berge, E., and del Zoppo, G. J. (2014). Thrombolysis for acute ischaemic stroke. Cochrane Database Syst. Rev. 2014:CD000213. doi: 10.1002/14651858.CD000213.pub3

Watanabe, T., Nagai, A., Sheikh, A. M., Mitaki, S., Wakabayashi, K., Kim, S. U., et al. (2016). A human neural stem cell line provides neuroprotection and improves neurological performance by early intervention of neuroinflammatory system. Brain Res. 1631, 194-203. doi: 10.1016/j.brainres. 2015.11.031

Wei, N., Yu, S. P., Gu, X., Taylor, T. M., Song, D., Liu, X. F., et al. (2013). Delayed intranasal delivery of hypoxic-preconditioned bone marrow mesenchymal stem cells enhanced cell homing and therapeutic benefits after ischemic stroke in mice. Cell Transplant. 22, 977-991. doi: 10.3727/096368912x657251

Wei, Z. Z., Gu, X., Ferdinand, A., Lee, J. H., Ji, X., Ji, X. M., et al. (2015). Intranasal delivery of bone marrow mesenchymal stem cells improved neurovascular regeneration and rescued neuropsychiatric deficits after neonatal stroke in rats. Cell Transplant. 24, 391-402. doi: 10.3727/096368915x686887

Xia, Y., Ling, X., Hu, G., Zhu, Q., Zhang, J., Li, Q., et al. (2020). Small extracellular vesicles secreted by human iPSC-derived MSC enhance angiogenesis through inhibiting STAT3-dependent autophagy in ischemic stroke. Stem Cell Res. Ther. 11:313. doi: 10.1186/s13287-020-01834-0

Xian, P., Hei, Y., Wang, R., Wang, T., Yang, J., Li, J., et al. (2019). Mesenchymal stem cell-derived exosomes as a nanotherapeutic agent for amelioration of inflammation-induced astrocyte alterations in mice. Theranostics 9, 5956-5975. doi: $10.7150 /$ thno.33872

Xin, H., Katakowski, M., Wang, F., Qian, J. Y., Liu, X. S., Ali, M. M., et al. (2017). MicroRNA cluster miR-17-92 cluster in exosomes enhance neuroplasticity and functional recovery after stroke in rats. Stroke 48, 747-753. doi: 10.1161/ strokeaha.116.015204

Xiong, X., Liu, L., and Yang, Q. (2016). Functions and mechanisms of microglia/macrophages in neuroinflammation and neurogenesis after stroke. Prog. Neurobiol. 142, 23-44. doi: 10.1016/j.pneurobio.2016.05.001

$\mathrm{Xu}, \mathrm{H}$., and Heilshorn, S. C. (2013). Microfluidic investigation of BDNF-enhanced neural stem cell chemotaxis in CXCL12 gradients. Small 9, 585-595. doi: 10. 1002/smll.201202208

Yamada, Y., Wakao, S., Kushida, Y., Minatoguchi, S., Mikami, A., Higashi, K., et al. (2018). S1P-S1PR2 axis mediates homing of muse cells into damaged heart for long-lasting tissue repair and functional recovery after acute myocardial infarction. Circ. Res. 122, 1069-1083. doi: 10.1161/circresaha.117.311648

Yamanaka, S. (2020). Pluripotent stem cell-based cell therapy-promise and challenges. Cell Stem Cell 27, 523-531. doi: 10.1016/j.stem.2020.09.014

Yamashita, T., and Abe, K. (2016). Recent progress in therapeutic strategies for ischemic stroke. Cell Transplant. 25, 893-898. doi: 10.3727/096368916x690548

Yamashita, T., Kawai, H., Tian, F., Ohta, Y., and Abe, K. (2011). Tumorigenic development of induced pluripotent stem cells in ischemic mouse brain. Cell Transplant. 20, 883-891. doi: 10.3727/096368910x 539092

Yanagisawa, D., Qi, M., Kim, D. H., Kitamura, Y., Inden, M., Tsuchiya, D., et al. (2006). Improvement of focal ischemia-induced rat dopaminergic dysfunction by striatal transplantation of mouse embryonic stem cells. Neurosci. Lett. 407, 74-79. doi: 10.1016/j.neulet.2006.08.007

Yang, B., Parsha, K., Schaar, K., Xi, X., Aronowski, J., and Savitz, S. (2016). Various cell populations within the mononuclear fraction of bone marrow contribute to the beneficial effects of autologous bone marrow cell therapy in a rodent stroke model. Transl. Stroke Res. 7, 322-330. doi: 10.1007/s12975-016-0462-x

Yang, T., Tsang, K. S., Poon, W. S., and Ng, H. K. (2009). Neurotrophism of bone marrow stromal cells to embryonic stem cells: noncontact induction and transplantation to a mouse ischemic stroke model. Cell Transplant. 18, 391-404. doi: 10.3727/096368909788809767

Yang, Y., Cai, Y., Zhang, Y., Liu, J., and Xu, Z. (2018). Exosomes secreted by adipose-derived stem cells contribute to angiogenesis of brain microvascular endothelial cells following oxygen-glucose deprivation in vitro through microRNA-181b/TRPM7 axis. J. Mol. Neurosci. 65, 74-83. doi: 10.1007/s12031018-1071-9

Yilmaz, G., Vital, S., Yilmaz, C. E., Stokes, K. Y., Alexander, J. S., and Granger, D. N. (2011). Selectin-mediated recruitment of bone marrow stromal cells in the postischemic cerebral microvasculature. Stroke 42, 806-811. doi: 10.1161/ strokeaha.110.597088

Yu, Y., Wu, R. X., Gao, L. N., Xia, Y., Tang, H. N., and Chen, F. M. (2016). Stromal cell-derived factor-1-directed bone marrow mesenchymal stem cell migration in response to inflammatory and/or hypoxic stimuli. Cell Adh. Migr. 10, 342-359. doi: 10.1080/19336918.2016.1139287

Yuan, M., Wen, S. J., Yang, C. X., Pang, Y. G., Gao, X. Q., Liu, X. Q., et al. (2013). Transplantation of neural stem cells overexpressing glial cell line-derived neurotrophic factor enhances Akt and Erk1/2 signaling and neurogenesis in rats after stroke. Chin. Med. J. (Engl.) 126, 1302-1309.

Zacharek, A., Chen, J., Cui, X., Li, A., Li, Y., Roberts, C., et al. (2007). Angiopoietin1/Tie2 and VEGF/Flk1 induced by MSC treatment amplifies angiogenesis and vascular stabilization after stroke. J. Cereb. Blood Flow Metab. 27, 1684-1691. doi: 10.1038/sj.jcbfm.9600475

Zhang, L. L., Zhang, H. T., Cai, Y. Q., Han, Y. J., Yao, F., Yuan, Z. H., et al. (2016). Anti-inflammatory effect of mesenchymal stromal cell transplantation and quercetin treatment in a rat model of experimental cerebral ischemia. Cell Mol. Neurobiol. 36, 1023-1034. doi: 10.1007/s10571-015-0291-6

Zhang, Z., Zhang, L., Jiang, Q., Zhang, R., Davies, K., Powers, C., et al. (2000). VEGF enhances angiogenesis and promotes blood-brain barrier leakage in the ischemic brain. J. Clin. Invest. 106, 829-838. doi: 10.1172/jci9369

Zhao, H., Han, Z., Ji, X., and Luo, Y. (2016). Epigenetic regulation of oxidative stress in ischemic stroke. Aging Dis. 7, 295-306. doi: 10.14336/ad.2015.1009

Zhu, J., Liu, Q., Jiang, Y., Wu, L., Xu, G., and Liu, X. (2015). Enhanced angiogenesis promoted by human umbilical mesenchymal stem cell transplantation in stroked mouse is Notch1 signaling associated. Neuroscience 290, 288-299. doi: 10.1016/j.neuroscience.2015.01.038

Zhu, Y., Guan, Y. M., Huang, H. L., and Wang, Q. S. (2014). Human umbilical cord blood mesenchymal stem cell transplantation suppresses inflammatory responses and neuronal apoptosis during early stage of focal cerebral ischemia in rabbits. Acta Pharmacol. Sin. 35, 585-591. doi: 10.1038/aps.2014.9

Conflict of Interest: The authors declare that the research was conducted in the absence of any commercial or financial relationships that could be construed as a potential conflict of interest.

Copyright (C) 2021 Zhou, Wang, Gao, Fu, Cao, Peng, Zhuang, Hu, Shao and Wang. This is an open-access article distributed under the terms of the Creative Commons Attribution License (CC BY). The use, distribution or reproduction in other forums is permitted, provided the original author(s) and the copyright owner(s) are credited and that the original publication in this journal is cited, in accordance with accepted academic practice. No use, distribution or reproduction is permitted which does not comply with these terms. 